\title{
Atomistic organization and characterization of tube-like assemblies comprising peptide- polymer conjugates: computer simulation studies
}

\author{
Oscar Bertran, ${ }^{a}$ David Curcó, ${ }^{b}$ David Zanuy ${ }^{c}$ and Carlos Alemán *cd
}

Received 8th May 2013, Accepted 5th June 2013

DOI: $10.1039 / c 3 f d 00079 f$

The structure and stability of the nanotube obtained by assembling peptidepolymer conjugates consisting of two poly( $n$-butyl acrylate) blocks coupled to the cyclic (D-alt-L)-octapeptide cyc[(L-GIn-D-Ala-L-Lys-D-Ala) $\left.)_{2}\right]$, have been investigated at the molecular level using atomistic molecular dynamics simulations. The effect of the wrapping polymer shells in the tube-like core, which consists of stacked $\beta$-sheet cyclopeptides, has been examined by simulating assemblies of both unsubstituted cyclopeptides, and conjugates in chloroform and $\mathrm{N}, \mathrm{N}$-dimethylformamide solutions. Furthermore, the influence of the environment has been investigated by comparing conjugate assemblies in solution with those deposited on mica. In addition, nanotubes stabilized by $\beta$-sheet-like hydrogen bonds between both parallel and antiparallel oriented cyclopeptides have been considered in all cases. The results, which have been analysed in terms of energy contributions, partial radial distribution functions, inter-subunit distances, shape of the cyclopeptide ring, internal van der Waals diameters, and both height and width of the nanostructures deposited on mica, have provided important microscopic insights. For example, analysis of both the energy terms and the structural dynamics obtained for the different assemblies indicate that the mica surface interacts more favourably with the parallel assembly than with the antiparallel ones, whereas the only configuration that is structurally stable in solution is the latter. Furthermore, adsorption onto the solid substrate produces a small deformation of the cylindrical molecular system.

\footnotetext{
${ }^{a}$ Departament of Applied Physics, EEI, Universitat Politècnica de Catalunya, Pça Rei 15, Igualada 08700, Spain ${ }^{b}$ Departament d'Enginyeria Química, Facultat de Química, Universitat de Barcelona, Martí i Franques 1, Barcelona E-08028, Spain

'Departament of Chemical Engineering, ETSEIB, Universitat Politècnica de Catalunya, Diagonal 647, Barcelona E-08028, Spain. E-mail: carlos.aleman@upc.edu

${ }^{d}$ Centre for Research in Nano-Engineering, Universitat Politècnica de Catalunya, Edifici C', C/Pasqual $i$ Vila $s / n$, Barcelona E-08028, Spain
} 


\section{Introduction}

The combination of a segment of biological origin with a synthetic polymer block leads to hybrid macromolecules, which are usually called polymer bioconjugates. ${ }^{1}$ In the specific case of integrated peptides the term peptide-polymer conjugate is most frequently used. These kinds of conjugates, which combine the precise chemical structure and functionality of peptides with the stability, functions and processability of synthetic polymers, are expected to be materials with practical applications in many fields. In spite of this, conjugation of peptides with poly(ethylene oxide) (PEO) has been the central topic of research for a few decades. ${ }^{2-8}$ However, with the recent explosion of the fields of nanotechnology and biotechnology, peptide-polymer conjugates are receiving increasing attention in materials science. ${ }^{9-11}$ As a consequence, the design and fabrication of peptide-polymer conjugates has become a rapidly expanding field of interdisciplinary research in the past few years, which involved not only a platform of synthetic macromolecules and peptides but also a palette of strategies to produce different architectures.

The strategies for the fabrication of well-defined peptide-polymer conjugates have been recently reviewed. ${ }^{12-14}$ In general, the preparation strategies for peptide-polymer conjugates can be categorized into four main approaches: (1) Coupling strategies, in which peptide segments are coupled to preformed synthetic molecules using one or more reactive sites; (2) Grafting strategies, in which the polymer is grown from the peptide segment; (3) Inverse conjugation strategy, where the peptide is sequentially assembled on an already formed polymer; and (4) Macromonomer strategies, which consist of the polymerization of short peptides with a polymerizable functionality. All these approaches provide hybrid molecules able to adopt different 3D organizations, the latter being defined through spontaneous or controlled self-assembly processes. ${ }^{15}$ The rules for such assemblies depend on the peptide secondary structure.

The relationship between peptide sequence and secondary structure motif is better developed for the $\alpha$-helix than for the $\beta$-sheet structure. However, within the field of materials science, more progress has been made in the hierarchical self-assembly of conjugates made with $\beta$-sheet-forming peptides. Fig. 1 summarizes the different types of $3 \mathrm{D}$ organizations formed by peptide-polymer conjugates via self-assembly of $\beta$-sheets. In these nanostructures the self-assembly process is dominated by the peptide organizer unit, which can correspond to a linear peptide, a pre-organized template or a cyclic system. Linear ${ }^{\mathbf{1 6}, 17}$ and preorganized $^{18,19}$ peptides produce well-defined nano- or microtapes while cyclic peptides $^{20,21}$ form self-assembled nanotubes.

Self-assembled peptide-based nanotubes have gained broad attention because of their high biocompatibility and the extraordinary ability to control their properties through modifications introduced to the monomeric unit. ${ }^{22}$ Although small linear peptides ${ }^{23-25}$ and even protein fragments extracted from natural $\operatorname{motifs}^{26-30}$ (e.g. left-handed $\beta$-helices) can be also used as organizer units of pepide-based nanotubes (Fig. 2a), hollow nanoassemblies made of cyclic peptides comprised of alternating $\mathrm{D}^{-}$and $\mathrm{L}$-amino acids [i.e. (D-alt- $\mathrm{L}$ )-cyclopeptides] have received special attention since their diameter is precisely controlled by the number of amino acids in the sequence (Fig. 2b). ${ }^{31-33}$ Within the latter context, the 


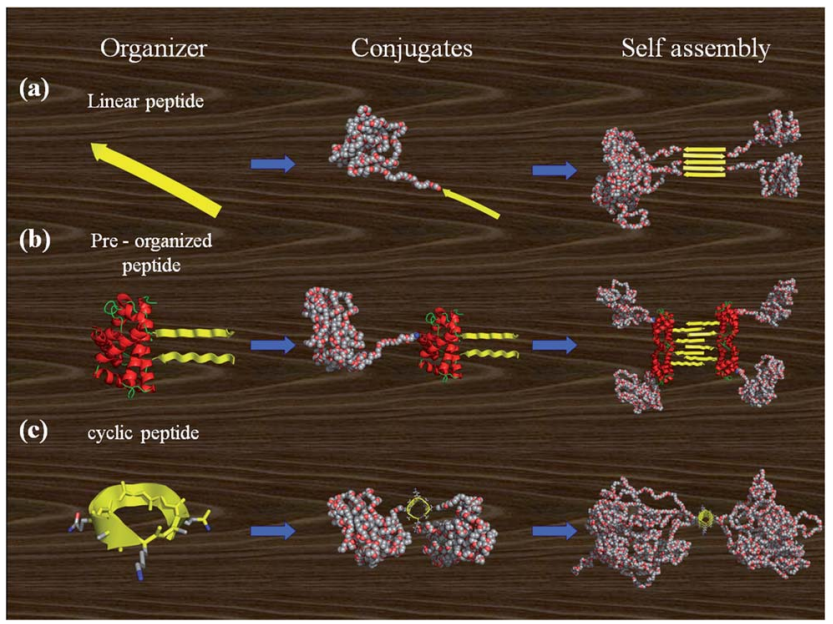

Fig. 1 Peptide-guided organization via self-assembly of peptide-polymer conjugates. The assembly process is in all cases dominated by the $\beta$-sheet-forming peptides.
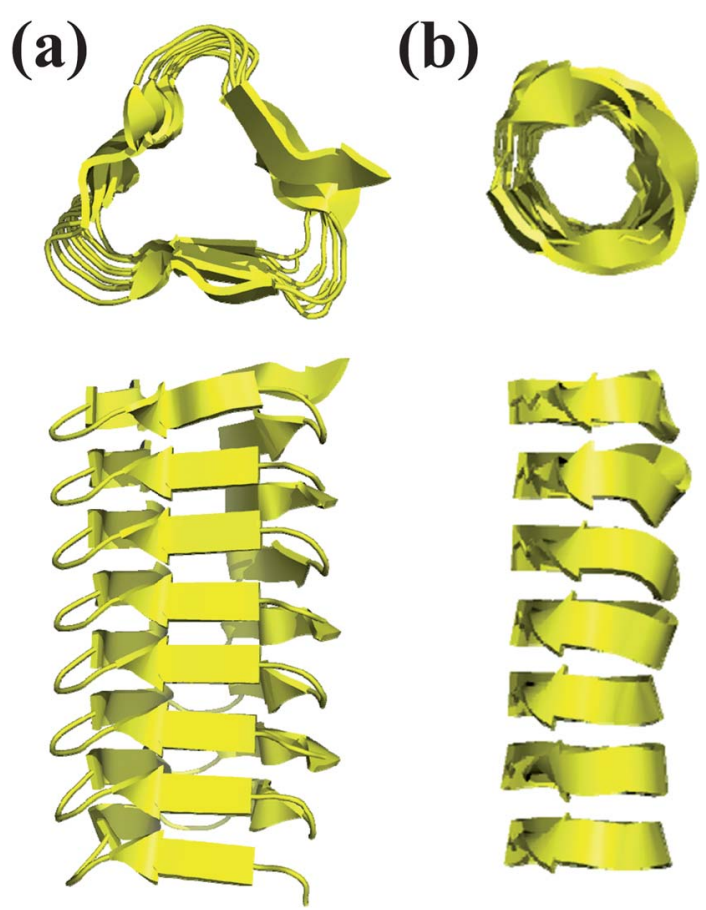

Fig. 2 Hollow nanotubes made of (a) protein fragments arranged in a left-handed $\beta$-helix conformation and (b) cyclic peptides comprised of alternating $\mathrm{D}$ - and L-amino acids.

pioneering work of Ghadiri and co-workers ${ }^{31,34,35}$ deserves special attention. These authors demonstrated that cyclic peptides made of $\alpha$-amino acids with alternating chirality show an interesting self-assembly behavior to tubular ring stacks 
at relatively small ring sizes. Recent studies extended this behavior to peptidepolymer conjugates, proving that cyclic $\mathrm{D}, \mathrm{L}-\alpha$-peptides are highly successful as organized units for the peptide-guided organization of hybrid molecules. ${ }^{21,36-40}$

Within the context of self-assembled nanotubes made of conjugates comprising cyclic peptides as aggregator domains, the work of ten Cate et al. ${ }^{21}$ is particularly relevant because of the synthetic process, which is gram scale, and the potential applications of the observed supramolecular 3D organization. More specifically, in that study two poly( $n$-butyl acrylate) blocks (PnBA) were coupled in solution to the cyclic (D-alt-L)-octapeptide developed by Ghadiri, ${ }^{31,41}$ cyc [(L-Gln-D-Ala-L-Lys-D-Ala) $)_{2}$ ] (Fig. 3a), using standard activation chemistry. The selective coupling sites for the anchoring of the PnBA blocks correspond to the two L-Lys residues, which are located at opposite sides of the cycle, leading to the cyc[(L-Gln-D-Ala-L-Lys-D-Ala $\left.)_{2}\right]-(\mathrm{P} n \mathrm{BA})_{2}$ conjugate (Fig. 3b). This system showed
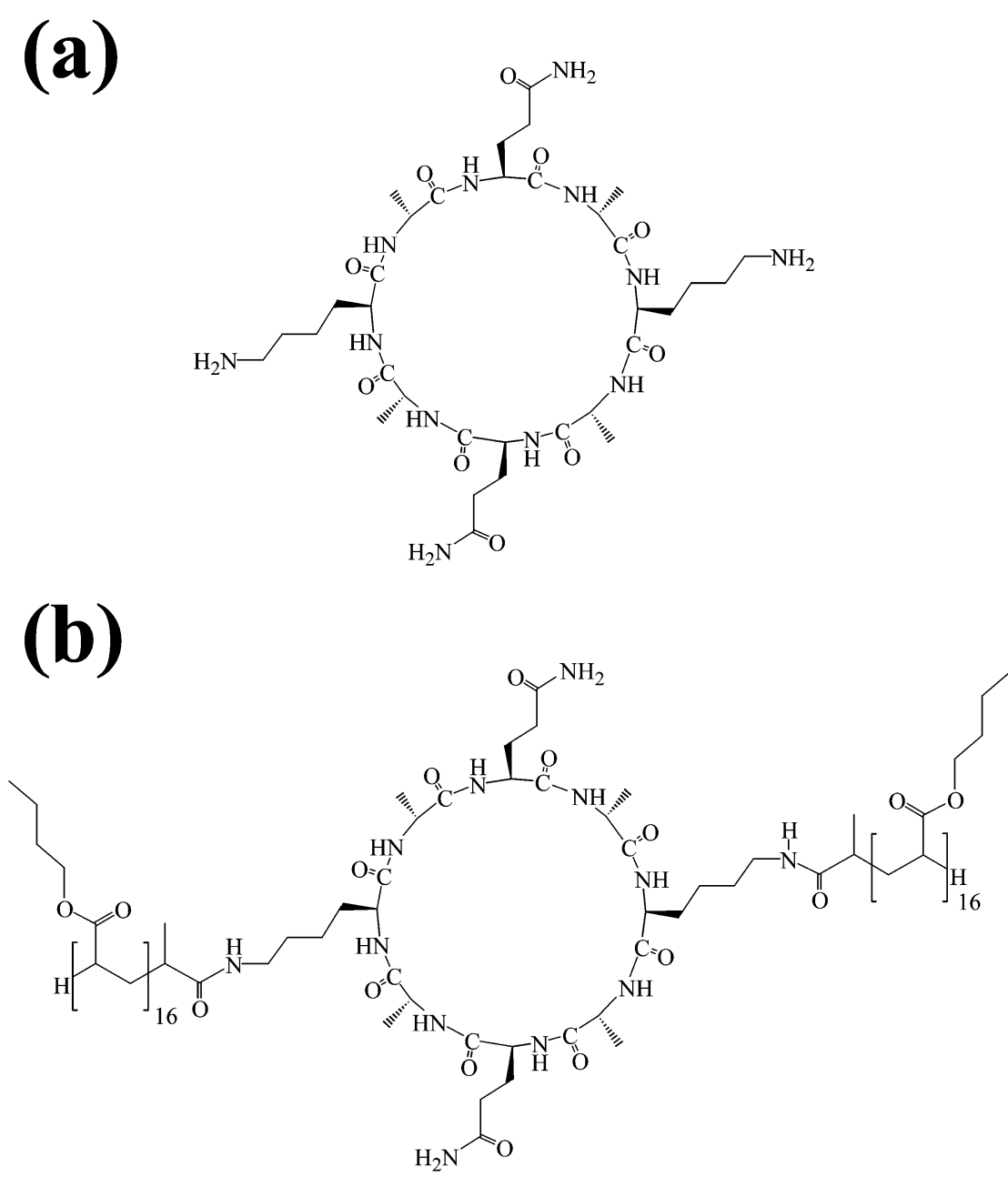

Fig. 3 Chemical structure of (a) cyc[(L-Gln-D-Ala-L-Lys-D-Ala $\left.)_{2}\right]$ and (b) cyc[(L-Gln-D-Ala-L-Lys-D-Ala $\left.)_{2}\right]-$ $(\mathrm{PnBA})_{2}$. 
uniform tube-like structures in solution and in a solvent-free environment (i.e. deposited on a mica substrate). In addition, these nanotubes were found to organize further into fibre networks because of the entanglements of the PnBA blocks. It is worth noting that cyc[(L-Gln-D-Ala-L-Lys-D-Ala $\left.)_{2}\right]-(\mathrm{P} n \mathrm{BA})_{2}$ nanotubes present a functionalizable exterior and a hollow interior, making this conjugate suitable for multiple applications.

Atomistic simulations on assembled peptides have been extensively reported in the past decade, ${ }^{42-48}$ with the results allowing us not only to get microscopic information about the association process at both kinetic and thermodynamic levels but also to complement experimental information. Despite such valuable contributions, atomistic computer simulations on peptide-polymer conjugates have been frequently restricted to the examination of the behaviour of individual molecules (i.e. the interaction between the two components of the hybrid molecule), ${ }^{49-51}$ limiting drastically their interest. Atomistic modeling of assembled conjugates is very challenging because of both their 3D organization complexity reflecting crowding, excluded volumes and multiphasic interactions, and, especially, their huge dimensions. Thus, in spite of the interest in peptide-polymer assemblies, the significant amount of computational resources needed to describe their chemical details and structural properties have severely restricted their atomistic modeling. However, computational advances, especially in terms of both parallel computer architectures and efficient scalability of computer programs, currently allow the study of chemical systems that were unaffordable a few years ago.

This work provides detailed atomistic investigation of the dynamical effects associated to the cyc[(L-Gln-D-Ala-L-Lys-D-Ala $\left.)_{2}\right]-(\mathrm{P} n \mathrm{BA})_{2}$ assembly. For this purpose, Molecular Dynamics (MD) simulations have been carried out in the two environments experimentally considered by ten Cate et al. ${ }^{21}$ (i.e. the hybrid in solution and deposited onto mica substrate). Although the self-assembly of cyclic peptides into nanotube structures typically occurs through the formation of $\beta$-sheet-like hydrogen bonding between antiparallel oriented molecules ${ }^{32,33}$ and, indeed, this arrangement was also proposed for the cyc[(L-Gln-D-Ala-L-Lys-D-Ala $)_{2}$ ]$(\mathrm{P} n \mathrm{BA})_{2},{ }^{21} \mathrm{MD}$ simulations have been performed on assemblies formed by a parallel or antiparallel arrangement of the conjugate molecules. The results have provided information about the influence of both solvent molecules and inorganic surfaces in the structure and the relative stability of the parallel and antiparallel assemblies. Moreover, the dynamics of the hybrid has been compared with that of cyc[(L-Gln-D-Ala-L-Lys-D-Ala $\left.)_{2}\right]$, results allowing us to ascertain the impact of the PnBA blocks on both the atomistic organization and stability of the peptide organizer.

\section{Methods}

\section{Molecular systems}

Three systems, each one with two different configurations, have been simulated and compared in this work:

(1) An assembly of 13 cyclopeptides cyc[(L-Gln-D-Ala-L-Lys-D-Ala) 2 ] (Fig. 3a) in both chloroform and $N, N$-dimethylformamide (DMF) solutions. The resulting nanotube was constructed considering that the ring-shaped peptide subunits stack through both antiparallel and parallel $\beta$-sheet hydrogen bonding. Fig. 4 


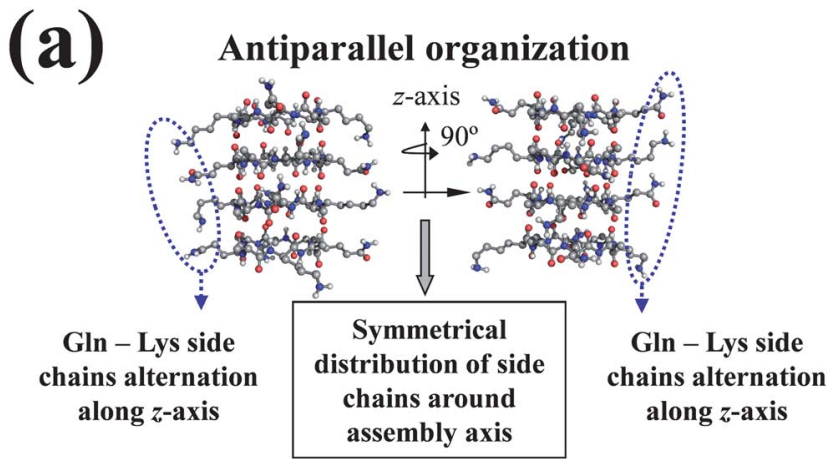

\section{Parallel organization}

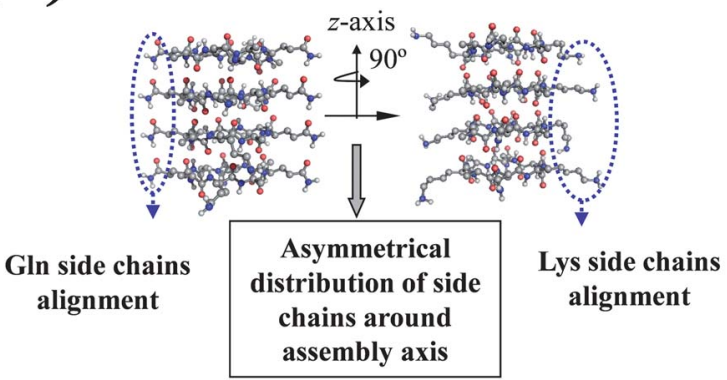

Fig. 4 Molecular schemes showing the main differences between the parallel and antiparallel $\beta$-sheet hydrogen bonding assemblies of cyc[(L-Gln-D-Ala-L-Lys-D-Ala $\left.)_{2}\right]$ : (a) a/cyc[(QALA) $\left.)_{2}\right]$ and (b) p/cyc $\left[(\mathrm{QALA})_{2}\right]$. Parallel and antiparallel configurations essentially differ in the organization of the Gln and Lys side chains.

displays the main differences between such two configurations, which essentially affect the distribution of the Gln and Lys side groups. Hereafter, the two resulting assemblies have been denoted a/cyc $\left[(\mathrm{QALA})_{2}\right]$ and p/cyc $\left[(\mathrm{QALA})_{2}\right]$ respectively. Each nanotube was placed at the center of a cubic simulation box ( $a=115 \AA$ ) containing 11000 explicit chloroform molecules or 10889 DMF molecules.

(2) An assembly of 13 units of cyc[(L-Gln-D-Ala-L-Lys-D-Ala $\left.)_{2}\right]-(\mathrm{P} n \mathrm{BA})_{2}$ (Fig. 3b) in DMF solution. Each polymer chain was formed by 16 repeated units, which corresponds to the degree of polymerization found by gel permeation chromatography. ${ }^{21}$ Nanotubes were constructed considering that the peptide subunits associate through antiparallel or parallel $\beta$-sheet hydrogen bonding, the resulting structures being abbreviated a/cyc $\left[(\mathrm{QALA})_{2}\right]-(\mathrm{P} n \mathrm{BA})_{2}$ and $\mathrm{p} / \mathrm{cyc}\left[(\mathrm{QALA})_{2}\right]-(\mathrm{P} n \mathrm{BA})_{2}$ respectively. Each nanotube was initially placed at the center of a cubic simulation box $(a=147 \AA$ ) containing 23318 explicit DMF molecules.

(3) An assembly of 13 units of cyc[(L-Gln-D-Ala-L-Lys-D-Ala $\left.)_{2}\right]-(\mathrm{P} n \mathrm{BA})_{2}$ on a mica surface. As in system (2), the number of repeat units of each polymer chain was 16. However, no solvent was considered in this case above the surface. The dimensions of the orthorhombic simulation box used for these simulations are: $a=207 \AA, b=215 \AA$ and $c=250 \AA$. It should be noted that the extension of the box in the $z$-direction is much larger than the extension of the system, leaving the 
system effectively periodic in the $x$ - and $y$-directions. As in the other two systems, nanotubes were constructed considering antiparallel and parallel configurations, the resulting structures being denoted a/m/cyc [(QALA $\left.)_{2}\right]-(\mathrm{P} n \mathrm{BA})_{2}$ and $\mathrm{p} / \mathrm{m} / \mathrm{cyc}$ $\left[(\mathrm{QALA})_{2}\right]-(\mathrm{P} n \mathrm{BA})_{2}$.

Generally speaking, the solvent-free case of (3) reflects the situation encountered in the atomic force experiments ("poor solvent"), while the explicit solvent molecules in (1) and (2) is expected to swell the peptide and the conjugate ("good solvent"). ${ }^{52}$

\section{Force-field}

The potential energy was expressed according to the functional form used by the AMBER force-field. ${ }^{53}$ All the parameters for the amino acids contained in the cyclic peptide and the conjugate were taken from the AMBER ff03 force-field, ${ }^{54}$ which produces structural and thermodynamical data for proteins and peptides in good agreement with experiments. ${ }^{54-56}$ In the ff03, atomic partial charges and main chain torsion potentials were derived from quantum mechanical calculations in solution. On the other hand, bonding and van der Waals parameters for the P $n$ BA block were taken from the Generalized AMBER Force Field (GAFF). ${ }^{57}$ Electrostatic parameters were explicitly obtained in this work by the applying the quantum mechanical method and fitting procedure used in the AMBER ff03 force-field. The OPLS model was used to describe the chloroform ${ }^{58}$ solvent while a modified OPLS-AA model was adopted for DMF. ${ }^{\mathbf{5 9 , 6 0}}$

The mica $\mathrm{K}_{1.0}\left[\mathrm{Si}_{3} \mathrm{Al}_{1} \mathrm{O}_{8}\right]\left[\mathrm{Al}_{2} \mathrm{O}_{2}(\mathrm{OH})_{2}\right]$ surface was represented using the forcefield parameters reported by Heinz and co-workers. ${ }^{61}$ The unit cell dimensions provided by such parameters for this dioctahedral phyllosilicate are $a=2.585 \AA$, $b=2.690 \AA, c=2.004 \AA, \alpha=89.4^{\circ}, \beta=95.3^{\circ}$ and $\gamma=90.1^{\circ}$, which are very close to the experimental ones (i.e. $a=2.596 \AA$, $b=2.705 \AA$, $c=2.005 \AA, \alpha=\gamma=90^{\circ}$ and $\left.\beta=95.7^{\circ}\right) .^{62}$ The mica super cell model constructed in ref. 61 was kindly supplied by Dr Heinz and adapted to the dimensions of the simulation box described in the previous subsection. The thickness (i.e. extension in the $c$-direction) of this sheet model was $6.7 \AA$. In order to avoid the bending of the mica sheet during the MD simulations, the position of the oxygen atoms located at the lowest part of the surface was kept fixed in the $z$-direction during the simulations (i.e. displacements for such atoms were allowed in the $x$ - and $y$-directions only).

The atom pair cut-off distance was set at $14.0 \AA$ to compute the van der Waals interactions. In order to avoid discontinuities in the potential energy function, non-bonding energy terms were forced to slowly converge to zero, by applying a smoothing factor from a distance of $12.0 \AA$ A Electrostatic interactions were extensively computed by means of Ewald summations. The real space term was defined by the van der Waals cutoff, while the reciprocal space was computed by interpolation into an infinite grid of points (particle mesh Ewald) with maximum space grid points being $1 \AA^{63}$

\section{Simulation details}

All simulations were performed using the NAMD 2.7 program. ${ }^{64}$ Each assembly of cyc $\left[(\text { L-Gln-D-Ala-L-Lys-D-Ala })_{2}\right]$ and cyc $\left[(\text { L-Gln-D-Ala-L-Lys-D-Ala })_{2}\right]-(\mathrm{P} n \mathrm{BA})_{2}$ in solution was submitted to 10000 steps of energy minimization (conjugate gradient) and this was the starting point for the equilibration protocol. After this, each 
system was heated at $298 \mathrm{~K}$ for $500 \mathrm{ps}$ in a NVT MD simulation, the resulting atom velocities and coordinates being used to start 2 ns of NPT MD (298 K and 1 bar pressure) simulation for density relaxation. The equilibrated density was 0.98 and $1.45 \mathrm{~g} \mathrm{~cm}^{\neg 3}$ for systems in DMF and chloroform, respectively. Productive simulations for systems in solution consisted of $15 \mathrm{~ns}$ of NPT MD (298 K, 1 bar pressure) runs, which were started using the coordinates and atom velocities at the end of the equilibration.

Equilibration of the a/m/cyc $\left[(\mathrm{QALA})_{2}\right]-(\mathrm{P} n \mathrm{BA})_{2}$ and $\mathrm{p} / \mathrm{m} / \mathrm{cyc}\left[(\mathrm{QALA})_{2}\right]-(\mathrm{P} n \mathrm{BA})_{2}$ assemblies was performed using the following protocol. Initially, the conjugate was placed at $\sim 15 \AA$ above the surface. After this, the potential energy of the system was minimized for 5000 steps using a conjugate gradient algorithm. Next, the whole system was submitted to $1 \mathrm{~ns}$ of NVT MD at $50 \mathrm{~K}$. This run led to the deposition of the assembled conjugate on the mica surface. Then, all atoms of the system were submitted to $2 \mathrm{~ns}$ of steady heating until the target temperature was reached $(298 \mathrm{~K})$ followed by $1 \mathrm{~ns}$ of thermal equilibration. Finally, $15 \mathrm{~ns}$ of NVT MD simulation were carried out for production.

Both the temperature and pressure were controlled by the weak coupling method, the Berendsen thermobarostat, ${ }^{65}$ with the relaxation times used for the coupling being 1 and 10 ps for temperature and pressure, respectively. Bond lengths were constrained using the SHAKE algorithm. ${ }^{66}$ The numerical integration step was set to $2 \mathrm{fs}$ in all cases. Periodic boundary conditions using the nearest image convention were applied in all directions for the assemblies in solution. The nonbonded pair list was updated every 5 steps.

\section{Analyses}

The structure of the simulated systems has been characterized by the partial radial distribution function of atom pairs, $g_{i j}(r)$. This function gives the probability of finding a pair of atoms a distance $r$ apart, relative to the probability expected for a completely random distribution at the same density. The partial radial distribution functions for a pair of atoms $i$ and $j$ was calculated as:

$$
g_{i j}(r)=\frac{V}{N_{i} N_{j}} \sum_{j=1}^{N_{j}} \frac{n_{i j}(r)}{4 \pi r^{2} \Delta r}
$$

where $N_{i}$ and $N_{j}$ are the number of atoms $i$ and $j$ in cell volume $V$ and $n_{i j}(r)$ is the number of atoms $j$ in the distance between $r-\Delta r / 2$ and $r+\Delta r / 2$ from atoms $i$.

The tubular structure was characterized through the temporally-averaged intersubunit distance $\left(d_{\mathrm{u}-\mathrm{u}}\right)$, which was calculated as the center of mass-to-center of mass between neighboring rings. For the rings of both the peptide and hybrid, the center of mass was calculated considering the backbone atoms that define the cycle. As all the simulated systems were constructed considering the assembly of 13 independent molecules, $d_{\mathrm{u}-\mathrm{u}}$ values have been obtained for each of the 12 pairs of assembled rings. The overall average of such 12 temporally averaged values has been denoted $\left\langle d_{\mathrm{u}-\mathrm{u}}\right\rangle$.

The circularity $(C)$ of the ring in the different assemblies was calculated using the following expressions:

$$
\sigma=\sqrt{\frac{\sum_{i=1}^{N}\left(R_{i}-R_{\mathrm{m}}\right)^{2}}{N}}
$$




$$
C=\sqrt{1-\frac{\sigma^{2}}{R_{\mathrm{m}}^{2}}}
$$

where $\sigma$ is the standard deviation or dispersion from the average geometric radius $\left(R_{\mathrm{m}}\right)$ of the distance between each of the $N$ backbone atoms of the cyclic peptide and the geometric center of the ring $\left(R_{i}\right)$. It should be noted that $C=1.0$ for a homogeneous and symmetric distribution of points on a circle.

\section{Results and discussion}

\section{Stability of the assemblies}

The stability of the parallel and antiparallel assemblies was initially examined through both a visual inspection of the recorded snapshots and analysis of the energies. Analysis of the trajectories obtained for the a/cyc[(QALA $\left.)_{2}\right]$ and p/cyc $\left[(\mathrm{QALA})_{2}\right]$ systems in solution revealed significant differences. Thus, the initial parallel arrangement, in which the 13 neighboring cyclic peptides were located at identical intermolecular distances, transformed into aggregates of smaller assemblies. More specifically, the parallel system involving 13 peptides transformed into 2-3 assemblies, each one composed of 3-7 molecules, after only $400 \mathrm{ps}$, independently of the solvent (Fig. 5a). In contrast, the antiparallel arrangement is able to stabilize the assembly formed by 13 molecules through hydrogen bonding networks (Fig. 5b) during the 15 ns trajectory. Although the two arrangements present stabilizing $\mathrm{N}-\mathrm{H} \cdots \mathrm{O}=\mathrm{C}$ intermolecular hydrogen bonds that involve the backbone peptide groups, the distribution of the Gln and
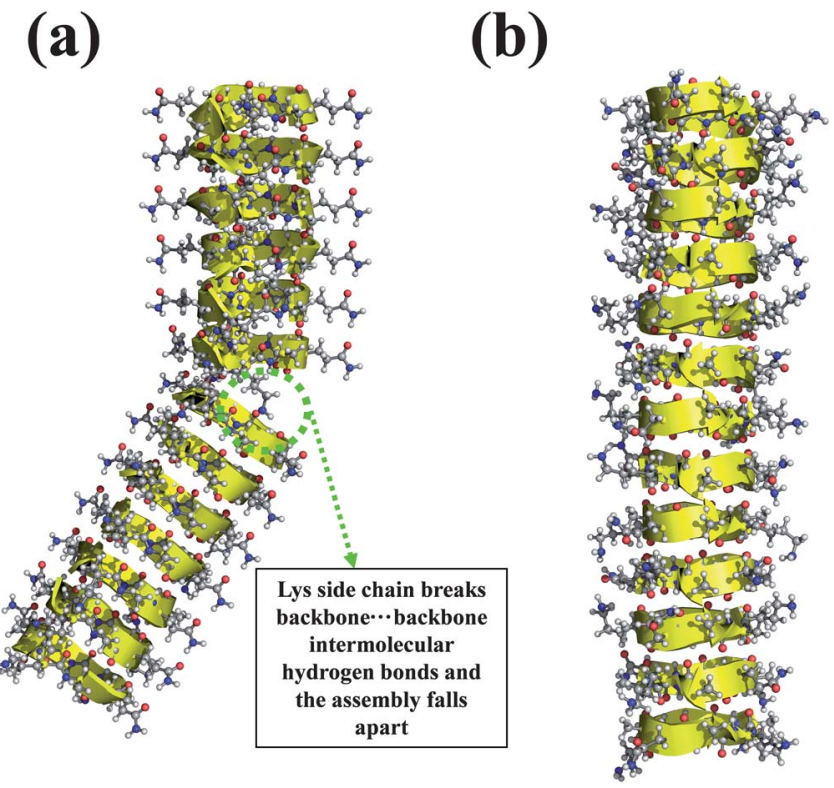

Fig. 5 Interrupted and stable self-assembly obtained from MD simulations of (a) p/cyc[(QALA) $\left.)_{2}\right]$ and (b) a/cyc $\left[(\mathrm{QALA})_{2}\right]$, respectively, in DMF solution. Structures were taken from snapshots recorded at 400 ps (a) and 15 ns (b). 
Lys side groups is completely different. The antiparallel disposition favors the formation of very stable cooperative assemblies because of the attractive interactions between the Gln and Lys side chains of neighboring peptides (Fig. 4a). Thus, these residues are arranged alternately facilitating the formation of side chain-side chain electrostatic interactions. In the parallel arrangement the Lys side groups of neighboring peptides confront one another, producing electrostatic repulsions (Fig. 4b). In order to alleviate such unfavorable interactions, the Lys side chains adopt different conformations, provoking in some case the rupture of backbone $\cdots$ backbone intermolecular hydrogen bonds (Fig. 5a).

Table 1 compares the most relevant energetic components derived from the a/ cyc $\left[(\mathrm{QALA})_{2}\right]$ trajectories in DMF and chloroform solutions (i.e. p/cyc $\left[(\mathrm{QALA})_{2}\right]$ results are not displayed because of the fragmentation of the assembly). More specifically, Table 1 lists the average values of the total energy associated with the peptide $\left(E_{\mathrm{tot}}^{\mathrm{pep}}\right)$, which has been divided into its bonding (i.e. stretching, bending and torsion interactions; $\left.E_{\text {bond }}^{\text {pep }}\right)$, van der Waals $\left(E_{\mathrm{vdW}}^{\mathrm{pep}}\right)$ and electrostatic $\left(E_{\mathrm{ele}}^{\mathrm{pep}}\right)$ contributions, and the average of the interaction energy between the peptide and the solvent, $E_{\mathrm{nt}}^{\text {pep-sol }}$. As can be seen, the $E_{\mathrm{tot}}^{\text {pep }}$ values are very similar for the two environments, indicating that the solvent does not affect the structure of the antiparallel assembly. Furthermore, the nanotube, whose stability is essentially dominated by the electrostatic contribution (i.e. $E_{\mathrm{ele}}^{\mathrm{pep}}$ is lower than $E_{\mathrm{vdW}}^{\mathrm{pep}}$ by one order of magnitude), interacts similarly with the two solvents.

Inspection of the results obtained for the two configurations of cyc[(L-Gln-DAla-L-Lys-D-Ala $\left.)_{2}\right]_{-}(\mathrm{P} n \mathrm{BA})_{2}$ in solution reveals similar findings to those discussed above for cyc[(L-Gln-D-Ala-L-Lys-D-Ala $\left.)_{2}\right]$. Thus, the p/cyc[(QALA $\left.)_{2}\right]-(\mathrm{P} n \mathrm{BA})_{2}$

Table 1 Energy analysis of the systems simulated in this work. ${ }^{a}$ All the energetic contributions are expressed in $\mathrm{kcal} \mathrm{mol}^{-1}$. $E_{\mathrm{tot}}^{\mathrm{pep}} / E_{\mathrm{tot}}^{\text {hyb }}$ refers to average total energy of the assembled system (peptide or hybrid) while $E_{\text {bond }}^{\text {pep }} / E_{\text {bond, }}^{\text {hyb }} E_{\mathrm{vdW}}^{\mathrm{pep}} / E_{\mathrm{vdW}}^{\text {hyb }}$ and $E_{\mathrm{ele}}^{\mathrm{pep}} / E_{\mathrm{ele}}^{\text {hyb }}$ correspond to the average of the bonding, van der Waals and electrostatic contributions, respectively, to the total energy. $E_{\mathrm{int}}^{\text {pep-sol }} / E_{\mathrm{int}}^{\text {hyb-sol}} / E_{\mathrm{int}}^{\text {hyb-mica }}$ is the interaction energy between the self-assembled system (peptide or hybrid) and the solvent or mica surface. Data are expressed as averages \pm 2 times the standard deviation

\begin{tabular}{|c|c|c|c|c|c|}
\hline System & $E_{\text {tot }}^{\text {pep }}$ & $E_{\text {bond }}^{\text {pep }}$ & $E_{\mathrm{vdW}}^{\mathrm{pep}}$ & $E_{\text {ele }}^{\text {pep }}$ & $E_{\mathrm{int}}^{\mathrm{pep}-\mathrm{sol}}$ \\
\hline & \multicolumn{5}{|c|}{ Peptide assemblies in solution ${ }^{b}$} \\
\hline $\mathrm{a} / \mathrm{cyc}\left[(\mathrm{QALA})_{2}\right]$ in $\mathrm{DMF}$ & $-1278 \pm 66$ & $2039 \pm 64$ & $-238 \pm 24$ & $\begin{array}{l}-3079 \pm \\
44\end{array}$ & $-3319 \pm 156$ \\
\hline \multirow{3}{*}{$\begin{array}{l}\mathrm{a} / \mathrm{cyc}\left[(\mathrm{QALA})_{2}\right] \text { in } \\
\text { chloroform }\end{array}$} & $-1330 \pm 76$ & $2049 \pm 74$ & $-237 \pm 26$ & $-3141 \pm$ & $-3399 \pm 134$ \\
\hline & $E_{\text {tot }}^{\text {hyb }}$ & $E_{\text {bond }}^{\text {hyb }}$ & $E_{\mathbf{v d w}}^{\text {hyb }}$ & $E_{\text {ele }}^{\text {hyb }}$ & $\begin{array}{l}E_{\text {int }}^{\text {hyb-sol }} \text { or } E^{\text {hyb- }} \\
\text { mica } \\
\text { int }\end{array}$ \\
\hline & \multicolumn{5}{|c|}{ Self-assembly of the hybrid in DMF solution ${ }^{b}$} \\
\hline \multirow[t]{2}{*}{$\mathrm{a} / \mathrm{cyc}\left[(\mathrm{QALA})_{2}\right]-(\mathrm{P} n \mathrm{BA})_{2}$} & $\begin{array}{l}-1959 \pm \\
172\end{array}$ & $\begin{array}{l}6220 \pm \\
158\end{array}$ & $\begin{array}{l}-1920 \pm \\
74\end{array}$ & $\begin{array}{l}-6260 \pm \\
48\end{array}$ & $-6529 \pm 126$ \\
\hline & \multicolumn{5}{|c|}{ Self-assembly of the hybrid deposited on mica } \\
\hline $\mathrm{a} / \mathrm{m} / \mathrm{cyc}\left[(\mathrm{QALA})_{2}\right]-(\mathrm{P} n \mathrm{BA})_{2}$ & $-3176 \pm 74$ & $\begin{array}{l}6534 \pm \\
124\end{array}$ & $\begin{array}{l}-3132 \pm \\
58\end{array}$ & $\begin{array}{l}-6580 \pm \\
58\end{array}$ & $-2193 \pm 90$ \\
\hline $\mathrm{p} / \mathrm{m} / \mathrm{cyc}\left[(\mathrm{QALA})_{2}\right]-(\mathrm{P} n \mathrm{BA})_{2}$ & $\begin{array}{l}-2823 \pm \\
132\end{array}$ & $\begin{array}{l}6450 \pm \\
116\end{array}$ & $\begin{array}{l}-2948 \pm \\
62\end{array}$ & $\begin{array}{l}-6415 \pm \\
58\end{array}$ & $-3008 \pm 106$ \\
\hline
\end{tabular}

${ }^{a}$ Averages were carried out considering the three last ns of the $15 \mathrm{~ns}$ trajectory. ${ }^{b}$ Results for parallel assemblies are not displayed because of their fragmentation. 
assembly becomes destabilized after only 400 ps by undesired side chain-backbone interactions undergoing fragmentation (Fig. 6a), whereas the a/cyc $\left[(\mathrm{QALA})_{2}\right]-(\mathrm{P} n \mathrm{BA})_{2}$ nanotube remains stable during the whole trajectory (Fig. 6b). The coupling of the PnBA chains to the cyclic octapeptide through the L-Lys reduces the impact of the electrostatic interactions between the side groups of neighboring molecules on the control of the stability. Although the electrostatic contribution is about three times lower than the van der Waals contribution, in relative terms the latter decreases more than the former. The high stability of the antiparallel configuration supports the organization proposed by ten Cate et al. ${ }^{21}$ on the basis of the FTIR and scattering (selected area electron diffraction) data, which were found to be in agreement with the antiparallel $\beta$-sheet present in (D-alt-L)-cyclopeptides. ${ }^{20}$

Finally, both the parallel and antiparallel arrangements of the hybrid deposited on mica remained stable with the 13 units associated within a single assembly during the whole trajectory. Details of the organization of the assembled peptides and $\mathrm{P} n \mathrm{BA}$ chains in $\mathrm{p} / \mathrm{m} / \mathrm{cyc}\left[(\mathrm{QALA})_{2}\right]-(\mathrm{P} n \mathrm{BA})_{2}$ and $\mathrm{a} / \mathrm{m} / \mathrm{cyc}$ $\left[(\mathrm{QALA})_{2}\right]-(\mathrm{P} n \mathrm{BA})_{2}$, which are depicted in Fig. 7a and b, respectively, are provided in next sections. On the other hand, Table 1 compares the average values of $E_{\mathrm{tot}}^{\text {hyb }}$, $E_{\mathrm{bond}}^{\text {hyb }}, E_{\mathrm{vdW}}^{\mathrm{hyb}}, E_{\mathrm{ele}}^{\text {hyb }}$ and $E_{\text {int }}^{\text {hyb-mica }}$ for the hybrid systems deposited on mica. As can be seen, all the contributions associated with $E_{\text {tot }}^{\text {hyb }}$ are more favorable for the two hybrids deposited on mica than for the antiparallel configuration in DMF solution. This feature is particularly remarkable for the $E_{\mathrm{vdW}}^{\mathrm{hyb}}$ contribution, which should be attributed to the surface-induced arrangement of the PnBA chains. Furthermore, analysis of the $E_{\text {int }}^{\text {hyb-mica }}$ component (Table 1 ) reveals that, interestingly, the parallel assembly interacts more favorably with the mica surface than the antiparallel one. This feature reveals that the stability of the parallel hybrid deposited on mica arises from the short-range interactions induced by the mica surface. Accordingly, the environmental anisotropy is responsible of the unexpected stabilization of the $\mathrm{p} / \mathrm{m} / \mathrm{cyc}\left[(\mathrm{QALA})_{2}\right]-(\mathrm{P} n \mathrm{BA})_{2}$ system.

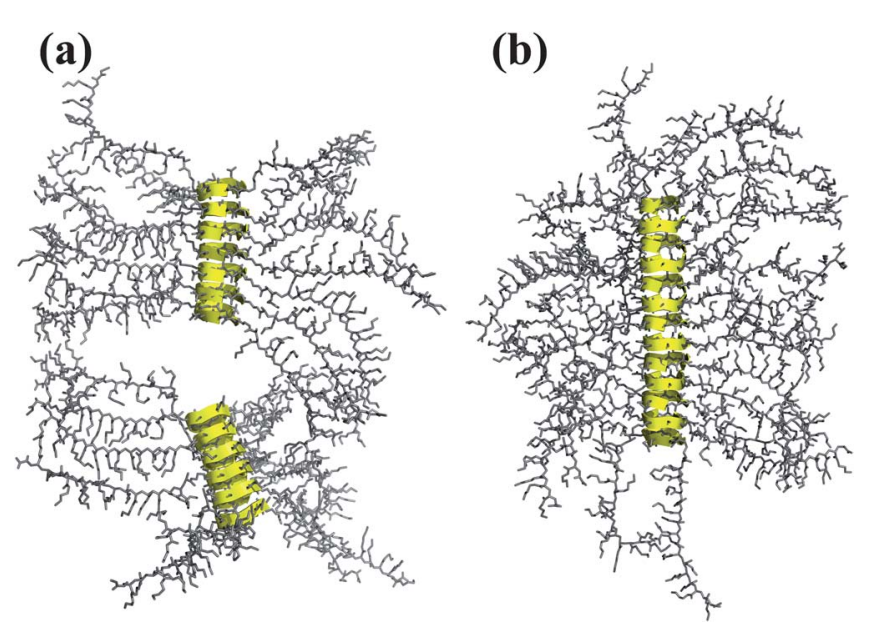

Fig. 6 Interrupted and stable self-assembly obtained from MD simulations of (a) p/cyc[(QALA) $)_{2}$ $(\mathrm{PnBA})_{2}$ and $(\mathrm{b}) \mathrm{a} / \mathrm{cyc}\left[(\mathrm{QALA})_{2}\right]-(\mathrm{PnBA})_{2}$, respectively. Structures were taken from snapshots recorded at 400 ps (a) and 15 ns (b). 

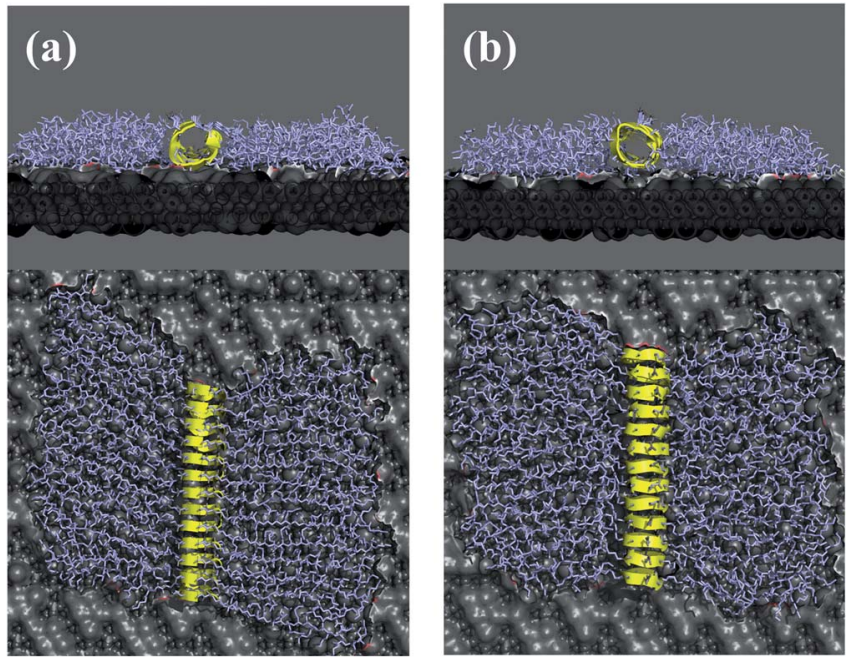

Fig. 7 Stable self-assembly obtained from MD simulations of (a) p/m/cyc[(QALA) $\left.{ }_{2}\right]-(P n B A)_{2}$ and (b) a/ $\mathrm{m} / \mathrm{cyc}\left[(\mathrm{QALA})_{2}\right]-(\mathrm{PnBA})_{2}$, respectively. Structures were taken from snapshots recorded at $15 \mathrm{~ns}$.

\section{Assembly of $\beta$-sheet motifs}

Fig. 8a represents the partial radial distribution function of the $\mathrm{C}^{\alpha}-\mathrm{C}^{\alpha}$ pairs belonging to different molecules, $g_{\mathrm{C} \alpha-\mathrm{C} \alpha}(r)$, for the a/cyc[(QALA $\left.)_{2}\right]$ system in both DMF and chloroform solutions (analysis of p/cyc[(QALA) $\left.)_{2}\right]$ has been omitted because of its lack of stability, see previous subsection). This function represents the probability of finding a pair of $\mathrm{C}^{\alpha}$ atoms in terms of intermolecular distances. The profiles obtained in DMF and chloroform solutions are practically identical, indicating that the assemblies in these environments are very similar. The first two peaks, which are sharp and narrow, are very close, being centered at $r=4.25$ and $5.75 \AA$. These two peaks correspond to the distance between pairs of neighboring $\mathrm{C}^{\alpha}$ atoms, which splits because consecutive cyclopeptides are shifted in the antiparallel arrangement. The average $r$ value, $5.0 \AA$, corroborates the stability of the $\beta$-sheet since it is very close to the inter-subunit distance typically observed for this secondary structure $(\sim 4.8 \AA) .{ }^{32}$ On the other hand, the rest of the peaks observed in the $g_{\mathrm{C} \alpha-\mathrm{C} \alpha}(r)$ are separated by $\sim 5 \AA$, as is characteristic of nanotubular assemblies.

Fig. 8b compares the $g_{\mathrm{C} \alpha-\mathrm{C} \alpha}(r)$ obtained for the stable configurations of cyc [(L-Gln-D-Ala-L-Lys-D-Ala $\left.)_{2}\right]-(\mathrm{P} n \mathrm{BA})_{2}$ in DMF solution (antiparallel) and deposited on mica (parallel and antiparallel). The profile obtained for the hybrid in DMF solution resembles those displayed in Fig. 8a for a/cyc[(QALA $\left.)_{2}\right]$, the most remarkable difference being the former shows a higher definition of the peaks in the $8.75 \AA<r<12.50 \AA$ region. In general, the $g_{\mathrm{C} \alpha-\mathrm{C} \alpha}(r)$ functions calculated for $\mathrm{p} / \mathrm{m} / \mathrm{cyc}\left[(\mathrm{QALA})_{2}\right]-(\mathrm{P} n \mathrm{BA})_{2}$ and $\mathrm{a} / \mathrm{m} / \mathrm{cyc}\left[(\mathrm{QALA})_{2}\right]-(\mathrm{P} n \mathrm{BA})_{2}$ do not show significant differences with respect the other three stable systems. However, it should be mentioned that the first two peaks, which are systematically obtained at $\sim 4.2$ and $\sim 5.8 \AA$ in all the studied antiparallel assemblies, merge into a single peak centered at $4.7 \AA$ in the $\mathrm{p} / \mathrm{m} / \mathrm{cyc}\left[(\mathrm{QALA})_{2}\right]-(\mathrm{P} n \mathrm{BA})_{2}$ system. As the parallel 
(a)

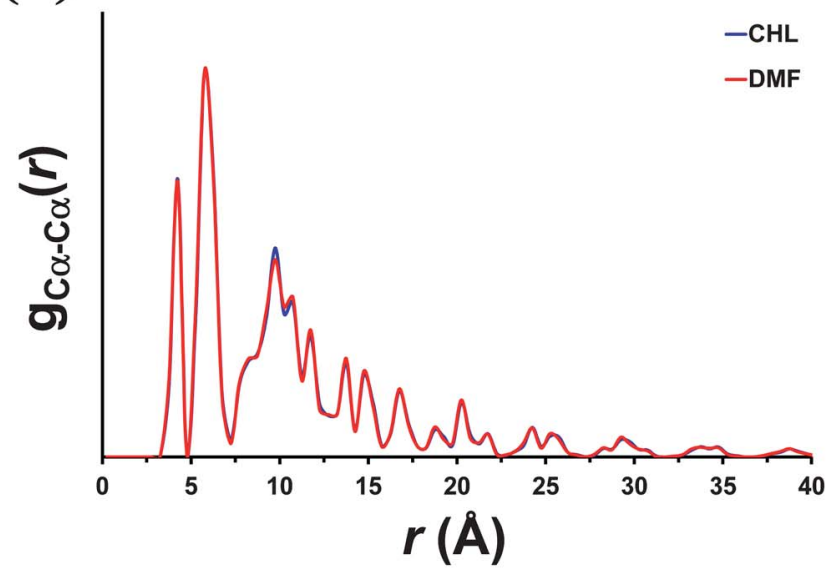

(b)

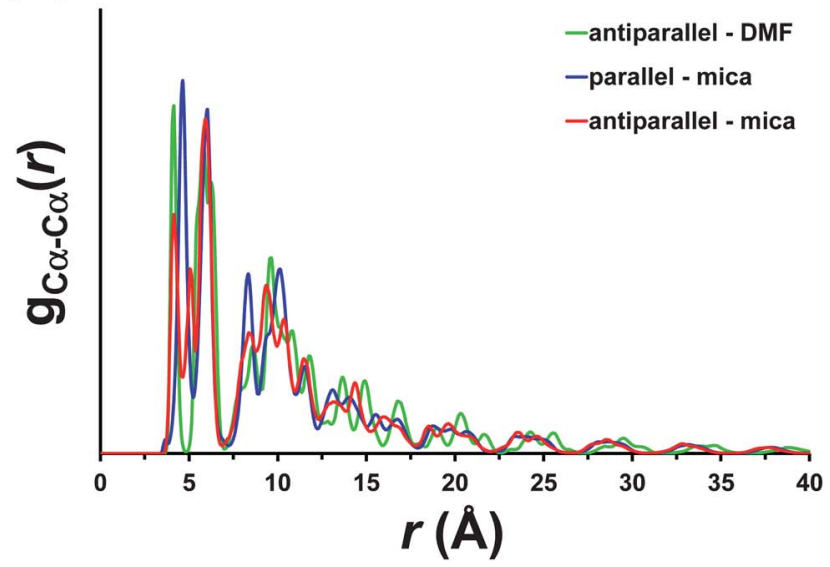

Fig. 8 Partial radial distribution function of the $C^{\alpha} \cdots C^{\alpha}$ pairs belonging to different molecules, $g_{C_{\alpha}-C_{\alpha}}(r)$, for the stable systems studied in this work: (a) a/cyc $\left[(\mathrm{QALA})_{2}\right]$ in chloroform $(\mathrm{CHL})$ and DMF solutions; and $(b) a / c y c\left[(Q A L A)_{2}\right]-(P n B A)_{2}, p / m / c y c\left[(Q A L A)_{2}\right]-(\operatorname{PnBA})_{2}$ and a/m/cyc $\left[(Q A L A)_{2}\right]-(P n B A)_{2}$.

disposition is obtained by copying the cyclopeptide, neighboring $C^{\alpha} \cdots C^{\alpha}$ pairs result in a single distance.

Fig. 9 represents the temporally-averaged inter-subunit distances, $d_{\mathrm{u}-\mathrm{u}}$, for the 12 pairs of assembled rings in the stable systems, whereas the overall $d_{\mathrm{u}-\mathrm{u}}$ averages, $\left\langle d_{\mathrm{u}-\mathrm{u}}\right\rangle$, are listed in Table 2 . As can be seen, the $\left\langle d_{\mathrm{u}-\mathrm{u}}\right\rangle$ values predicted for $\mathrm{a} /$ cyc $\left[(\mathrm{QALA})_{2}\right]$ in DMF and chloroform solutions are identical $(4.76 \pm 0.10 \AA)$ and practically matched the distance observed by Fourier-transform infrared spectroscopy, electron diffraction and X-ray crystallographic analyses $\left(4.73 \AA\right.$ A.$^{31,32,34,67}$ Moreover, $d_{\mathrm{u}-\mathrm{u}}$ remains practically constant along the whole nanotube reflecting again the high stability of the antiparallel cyclopeptide assembly. The results obtained for a/cyc[(QALA $\left.)_{2}\right]-(\mathrm{P} n \mathrm{BA})_{2}$ in DMF reveal a very similar behavior with $\left\langle d_{\mathrm{u}-\mathrm{u}}\right\rangle=4.78 \pm 0.14 \AA$ A Comparison with the average $d_{\mathrm{u}-\mathrm{u}}$ values along the 


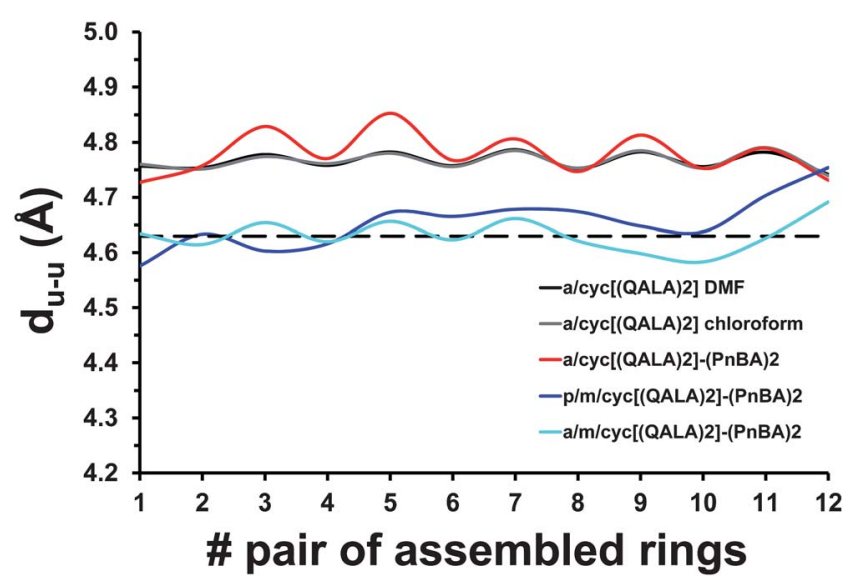

Fig. 9 Variation of the temporally-averaged inter-subunit distances, $d_{\mathrm{u}-\mathrm{u}}$, for the 12 pairs of assembled rings in the stable systems studied in this work. The experimental value determined using electron diffraction for the hybrid in a desolvated environment is represented by the black dashed line. The overall averages, $\left\langle d_{\mathrm{u}-\mathrm{u}}\right\rangle$, are listed in Table 2 .

Table 2 Structural and geometric calculated for the stable systems studied in this work

\begin{tabular}{|c|c|c|c|}
\hline & $\left\langle d_{\mathrm{u}-\mathrm{u}}\right\rangle(\AA)^{a}$ & $\langle C\rangle^{b}$ & $\left\langle D_{\mathrm{vdW}}\right\rangle(\AA)^{c}$ \\
\hline $\mathrm{a} / \mathrm{cyc}\left[(\mathrm{QALA})_{2}\right]$ DMF solution & $4.76 \pm 0.10$ & $0.9984 \pm 0.0014$ & $5.50 \pm 0.10$ \\
\hline $\mathrm{a} / \mathrm{cyc}\left[(\mathrm{QALA})_{2}\right]$ chloroform solution & $4.76 \pm 0.10$ & $0.9980 \pm 0.0022$ & $5.48 \pm 0.12$ \\
\hline $\mathrm{a} /$ cyc $\left[(\mathrm{QALA})_{2}\right]-(\mathrm{P} n \mathrm{BA})_{2}$ & $4.78 \pm 0.14$ & $0.9976 \pm 0.0022$ & $5.47 \pm 0.12$ \\
\hline $\mathrm{p} / \mathrm{m} / \mathrm{cyc}\left[(\mathrm{QALA})_{2}\right]-(\mathrm{P} n \mathrm{BA})_{2}$ & $4.65 \pm 0.12$ & $0.9970 \pm 0.0018$ & $5.21 \pm 0.12$ \\
\hline $\mathrm{a} / \mathrm{m} / \mathrm{cyc}\left[(\mathrm{QALA})_{2}\right]-(\mathrm{P} n \mathrm{BA})_{2}$ & $4.63 \pm 0.10$ & $0.9943 \pm 0.0034$ & $5.23 \pm 0.12$ \\
\hline
\end{tabular}

nanotube for the systems deposited on mica reveals a contraction higher than 0.1 $\AA$ A per pair of assembled neighboring rings. Thus, $\left\langle d_{\mathrm{u}-\mathrm{u}}\right\rangle=4.65 \pm 0.12$ and $4.63 \pm$ $0.10 \AA$ for $\mathrm{p} / \mathrm{m} / \mathrm{cyc}\left[(\mathrm{QALA})_{2}\right]-(\mathrm{P} n \mathrm{BA})_{2}$ and $\mathrm{a} / \mathrm{m} / \mathrm{cyc}\left[(\mathrm{QALA})_{2}\right]-(\mathrm{P} n \mathrm{BA})_{2}$, respectively. These values are in excellent agreement with the experimental value of $4.63 \AA$ determined by electron diffraction measurements on desolvated samples. ${ }^{21}$

\section{Shape of the cyclic octapeptide: circularity}

Molecular mechanics calculations in the gas-phase, which consisted of an energy minimization followed by a short MD simulation, of an isolated cyc[(L-Gln-D-Ala-LLys-D-Ala $)_{2}$ ] molecule, led to a circular ring shape with circularity $C=1.0$ and van der Waals internal diameter $D_{\mathrm{vdw}}=5.22 \AA$. The latter diameter is very similar to the pore diameter reported for single-stranded $\beta$-helices with 8.2 residues per turn (i.e. $4.7 \AA),{ }^{68}$ supporting the theory that this conformation is intrinsically favored for the octapeptide. Fig. 10a and $\mathrm{b}$ represent the time-averaged circularity and van der Waals internal diameter ( $C$ and $D_{\mathrm{vdw}}$, respectively, for each ring of the stable systems studied in this work; overall average values $\left(\langle C\rangle\right.$ and $\left.\left\langle D_{\mathrm{vdw}}\right\rangle\right)$ being listed in Table 2). 
(a)
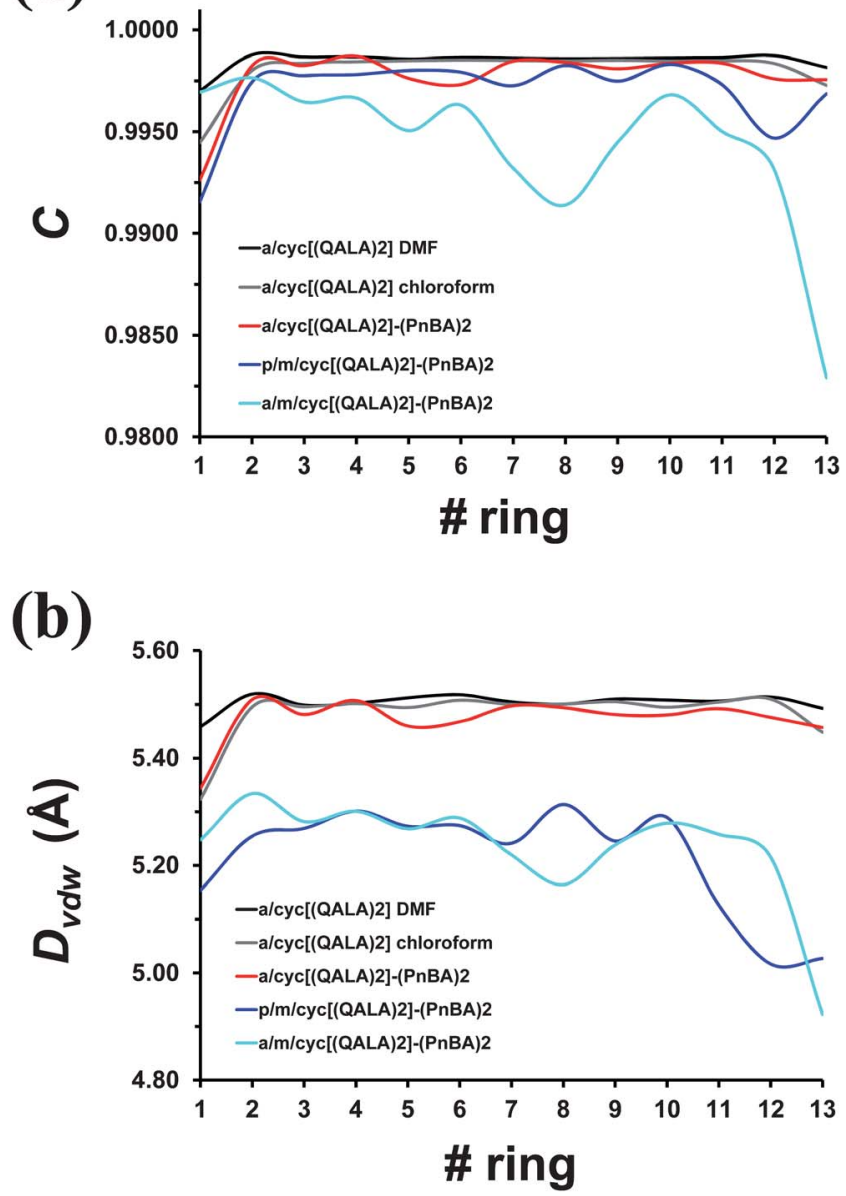

Fig. 10 Variation of the temporally-averaged circularity $(C)$ and internal van der Waals diameter $\left(D_{\mathrm{vdw}}\right)$ for the 13 rings of the stable systems studied in this work. The overall averages, $\langle C\rangle$ and $\left\langle D_{\mathrm{vdw}}\right\rangle$, are listed in Table 2.

The behavior of the assembled peptide in both DMF and chloroform solutions is analogous to that observed for the isolated peptide in the gasphase, indicating that the solvent does not affect the circularity and diameter of the rings. Thus, time-averaged values of $C$ and $D_{\mathrm{vdw}}$ ranged from 0.9944 to 0.9987 and from 5.32 to $5.46 \AA$, respectively, with distortions being larger at the ends of the nanotube for both parameters. In contrast, the circularity is affected by the incorporation of the PnBA blocks provoking a reduction of $C$ (Fig. 10a), this effect being more pronounced in mica than in DMF solution. Thus, the value of $\langle C\rangle$ decreases from $0.9976 \pm 0.0022$ for a/cyc[(QALA) $)_{2}$ $(\mathrm{P} n \mathrm{BA})_{2}$ to $0.9943 \pm 0.0034$ for a/m/cyc[(QALA $\left.)_{2}\right]-(\mathrm{P} n \mathrm{BA})_{2}$. In spite of such a reduction and the fluctuations displayed in Fig. 10a, distortions in the hybrid are still small and no relevant change is visually detected in the shape of the ring. The alteration induced by the mica surface in the circularity of the ring produces a reduction of the internal diameter, with the $D_{\mathrm{vdw}}$ values being 
around $0.3 \AA$ smaller for the hybrid deposited on mica than for the peptide in solution (Fig. 10b and Table 2).

On the other hand, analysis of the circularity in the p/cyc[(QALA $\left.)_{2}\right]$ and p/cyc $\left[(\mathrm{QALA})_{2}\right]-(\mathrm{P} n \mathrm{BA})_{2}$ systems reveals very significant distortions from the circular shape. Thus, the parameter $C$ decreases from $\sim 0.99$ to $\sim 0.78$ just before the 13-cyclopeptide assembly disrupts into aggregates of smaller assemblies. This effect is due to the formation of a strong interaction between the Lys side chains and the cyclopeptide backbone that, as mentioned above, is responsible for the destabilization of the parallel assemblies. This is illustrated in Fig. 11, which compares the circularity of a cyclopeptide contained in the $\mathrm{p} / \mathrm{cyc}\left[(\mathrm{QALA})_{2}\right]-$ $(\mathrm{P} n \mathrm{BA})_{2}$ system at the beginning of the MD simulation (i.e. after $200 \mathrm{ps}$ ), and when the backbone interacts with the Lys side chain of a neighboring unit (i.e. just before the fragmentation of the assembly).

\section{Organization of the poly(n-butyl acrylate) blocks}

Fig. 12a displays the partial radial distribution function of the $\mathrm{CH}_{2}-\mathrm{CHR}$ pairs belonging to the same PnBA block, $g^{\mathrm{S}} \mathrm{CH}_{2}-\mathrm{CHR}(r)$ (where $\mathrm{CH}_{2}$ and $\mathrm{CHR}$ refer to unsubstituted and substituted backbone carbon atoms of the polymer repeat unit), for the stable assemblies of the hybrid in solution and deposited on mica. The presence of narrow and sharp peaks suggests that the conformation adopted by the polymer remains relatively stable during the trajectory. The very high peak centered at $1.55 \AA$ corresponds to the $\mathrm{CH}_{2}-\mathrm{CHR}$ bond length while that centered at $2.85 \AA$ refers to the dihedral angle formed by the backbone atoms of two consecutive repeat units. More specifically, such a distance should be associated with a semi-extended arrangement (i.e. the distance expected for an ideal trans conformation is $3.0 \AA$ ). The rest of the peaks, which correspond to pairs of atoms separated by more than two repeat units, indicate a significant degree of
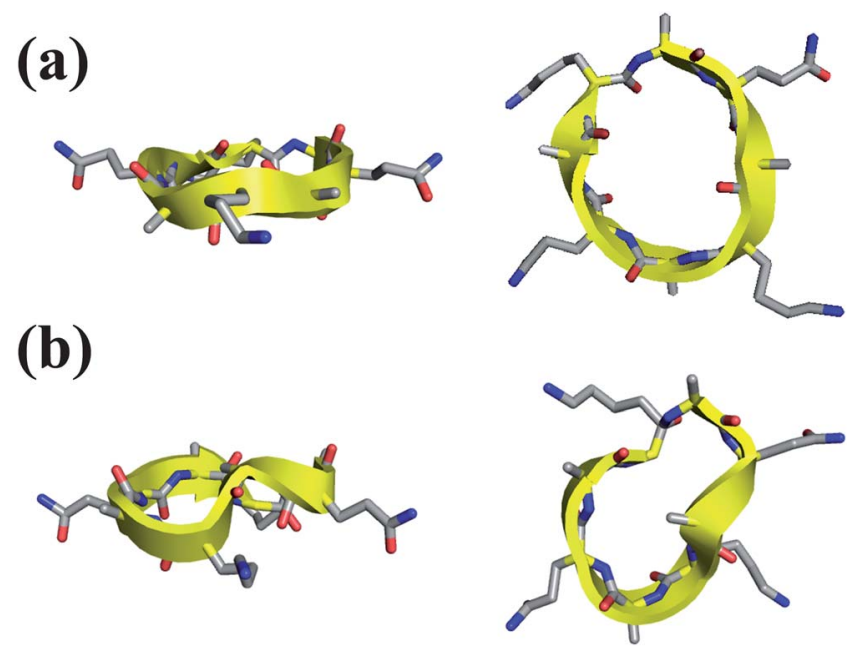

Fig. 11 Schematic pictures showing (a) the circular shape $(C=0.9948)$ of the cyclopeptide ring at the beginning of the MD simulation (snapshot recorded at $t=200 \mathrm{ps}$ ) and (b) the loss of the circular shape ( $C$ $=0.7816$ ) when the Lys side chain of a neighboring unit interacts with the backbone (snapshot recorded at $t=400 \mathrm{ps})$ for $\mathrm{p} / \mathrm{cyc}\left[(\mathrm{QALA})_{2}\right]-(\mathrm{PnBA})_{2}$. 

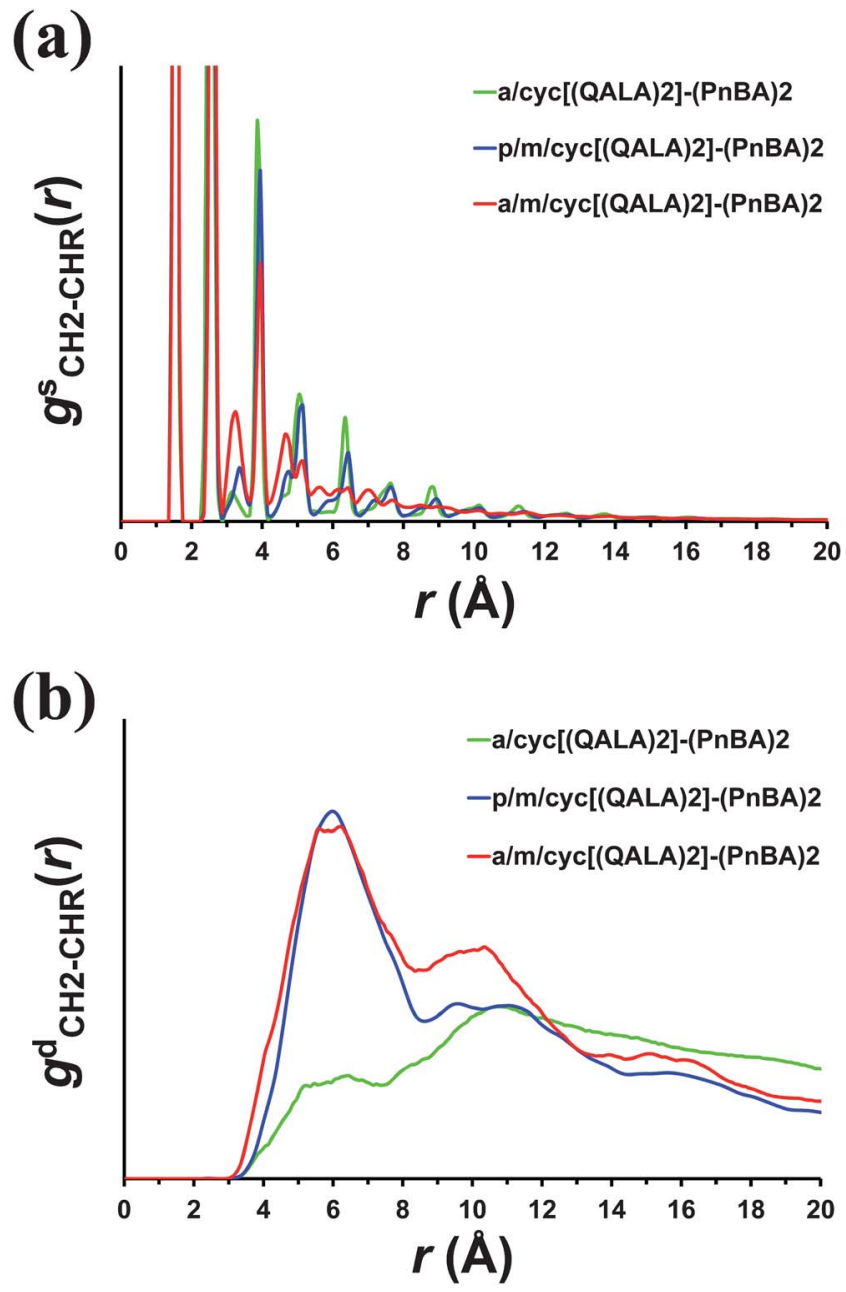

Fig. 12 Partial radial distribution function of the $\mathrm{CH}_{2}-\mathrm{CHR}$ pairs belonging to the $\mathrm{PnBA}$ blocks of the (a) same and (b) different molecules $\left(g^{\mathrm{s}} \mathrm{CH}_{2}-\mathrm{CHR}(r)\right.$ and $g^{\mathrm{d}} \mathrm{CH}_{2}-\mathrm{CHR}(r)$, respectively) for the stable assemblies studied in this work.

conformational regularity at the molecular level. This order is particularly remarkable for the hybrid in solution. Thus, a/cyc $\left[(\mathrm{QALA})_{2}\right]-(\mathrm{P} n \mathrm{BA})_{2}$ shows peaks with higher definition and narrower widths than the assemblies in mica, especially at distances larger than $5 \AA$. This feature should be attributed to the fact that environmental forces exerted on PnBA blocks are isotropic in solution, whereas the mica-induced forces are anisotropic affecting the molecular conformation. Additionally, the intramolecular conformational regularity of a/m/cyc[(QALA $\left.)_{2}\right]-$ $(\mathrm{P} n \mathrm{BA})_{2}$ extends to $r<6 \AA$ only while that of $\mathrm{p} / \mathrm{m} / \mathrm{cyc}\left[(\mathrm{QALA})_{2}\right]-(\mathrm{P} n \mathrm{BA})_{2}$ and a/cyc [(QALA $\left.)_{2}\right]-(\mathrm{P} n \mathrm{BA})_{2}$ reaches $r \approx 10-11 \AA$.

Fig. 12b represents the partial radial distribution function of the $\mathrm{CH}_{2}-\mathrm{CHR}$ pairs belonging to different PnBA blocks, $g^{\mathrm{d}} \mathrm{CH}_{2}-\mathrm{CHR}(r)$, for the stable assemblies in solution and deposited on mica. As can be seen, the hybrid in solution shows 
two broad and very ill-defined peaks centered at $\sim 6.0$ and $\sim 10.5 \AA$. This suggests that $\mathrm{P} n \mathrm{BA}$ chains belonging to different molecules do not follow any periodic pattern for the packing, as is clearly illustrated in the snapshot presented in Fig. 6b. Thus, the above mentioned peaks only capture the more probable interval of distances between relatively close neighboring pairs. The intermolecular order of the antiparallel assembly experiences an improvement upon deposition in mica. Thus, the two peaks are significantly higher and better defined when the isotropic DMF solution is replaced by an anisotropic environment. This shortrange order is reflected in the atomistic representation provided in Fig. $7 \mathrm{~b}$. Inspection of the $g^{\mathrm{d}} \mathrm{CH}_{2}-\mathrm{CHR}(r)$ profile obtained for $\mathrm{p} / \mathrm{m} / \mathrm{cyc}\left[(\mathrm{QALA})_{2}\right]-(\mathrm{P} n \mathrm{BA})_{2}$ indicates that the peak at $\sim 10.5 \AA$ becomes ill-defined with respect to that calculated for $\mathrm{a} / \mathrm{m} / \mathrm{cyc}\left[(\mathrm{QALA})_{2}\right]-(\mathrm{P} n \mathrm{BA})_{2}$, which should be attributed to the particular orientation of the PnBA chains onto the mica surface (Fig. 7a). Thus, although the polymer chains show regular conformations, as was discussed above (Fig. 12a), the attraction exerted by the inorganic surface produces a bending in the polymer chains that affects the intermolecular order.

\section{Height and width of the adsorbed hybrid}

Deformation of cylindrical molecular systems can be induced by their adsorption onto solid substrates. This feature has been clearly demonstrated by AFM images of bottle-brushes and dendronized polymers, which display a strong adsorption-induced flattening. ${ }^{69-72}$ However, deformability depends on the chemical nature of the molecules, being, for example, less important in dendronized polymers than in bottle-brush structures. In the particular case of cyc[(L-Gln-D-Ala-L-Lys-D-Ala $\left.)_{2}\right]-(\mathrm{P} n \mathrm{BA})_{2}$ nanotubes deposited on a mica substrate, the observed structure's height and width was found to be $14 \pm 2$ and $50 \AA$, respectively. ${ }^{21}$ The former value suggests that $\mathrm{P} n \mathrm{BA}$ chains avoid back-folding onto the peptide tube structure while the latter indicates that apparently the PnBA chains are folded onto the surface. MD simulations corroborate the lack of backfolding in $\mathrm{p} / \mathrm{m} / \mathrm{cyc}\left[(\mathrm{QALA})_{2}\right]-(\mathrm{P} n \mathrm{BA})_{2}$ and $\mathrm{a} / \mathrm{m} / \mathrm{cyc}\left[(\mathrm{QALA})_{2}\right]-(\mathrm{P} n \mathrm{BA})_{2}$, as is clearly illustrated in the representative snapshots displayed in Fig. 7a and b, respectively. In order to verify that such behavior is due to the strong interaction between PnBA chains and the mica substrate, the interaction energy between the hybrid and the substrate has been decomposed into two components. Table 3 compares the

Table 3 Decomposition of the interaction energy between the assembled hybrid and mica surface ( $E_{\mathrm{int}}^{\text {pep-mica }}$ in Table 1 ) into the components associated to the interaction of the substrate with the peptide nanotube ( $E_{\text {int }}^{\text {tube-mica }}$ ) and with the PnBA chains ( $E_{\text {int }}^{\text {pol-mica }}$ ). Furthermore, van der Waals and electrostatic contributions are shown for each component. Data are expressed as averages \pm 2 times the standard deviation

\begin{tabular}{lll}
\hline & $\mathrm{p} / \mathrm{m} / \operatorname{cyc}\left[(\mathrm{QALA})_{2}\right]-(\mathrm{P} n \mathrm{BA})_{2}$ & $\mathrm{a} / \mathrm{m} / \mathrm{cyc}\left[(\mathrm{QALA})_{2}\right]-(\mathrm{P} n \mathrm{BA})_{2}$ \\
\hline$E_{\text {int }}^{\text {pol-mica }}$ & $-2331 \pm 52$ & $-1736 \pm 40$ \\
van der Waals & $-906 \pm 22$ & $-768 \pm 20$ \\
Electrostatic & $-1425 \pm 52$ & $-967 \pm 38$ \\
$E_{\text {int }}^{\text {tube-mica }}$ & $-676 \pm 33$ & $-457 \pm 28$ \\
van der Waals & $-121 \pm 13$ & $-58 \pm 12$ \\
Electrostatic & $-554 \pm 36$ & $-399 \pm 30$
\end{tabular}


interaction energies of the mica substrate with the peptide nanotube and the PnBA chains ( $E_{\text {int }}^{\text {tube-mica }}$ and $E_{\text {nnt }}^{\text {pol-mica }}$, respectively), which in turn have been separated into their electrostatic and van der Waals contributions. As can be seen, $E_{\mathrm{nt}}^{\text {pol-mica }}$ is 3.5-4 times more stabilizing than $E_{\mathrm{int}}^{\text {tube-mica }}$ for both the parallel and the antiparallel assemblies. Moreover, the strength of the mica-P $n \mathrm{BA}$ interactions arises from the two non-bonding contributions, even though the most important difference with respect to peptide-mica interactions corresponds to the van der Waals one.

In order to provide an atomistic view of both the deformability of the peptide nanotube, the height $(h)$ and width $(w)$ of peptide nanotubes in a/m/cyc[(QALA $\left.)_{2}\right]-$ $(\mathrm{P} n \mathrm{BA})_{2}$ and $\mathrm{p} / \mathrm{m} / \mathrm{cyc}\left[(\mathrm{QALA})_{2}\right]-(\mathrm{P} n \mathrm{BA})_{2}$ have been determined and compared with the diameter of the nanotubes in a/cyc $\left[(\mathrm{QALA})_{2}\right]-(\mathrm{P} n \mathrm{BA})_{2}$. Fig. 13a shows the distribution of mass per molecule involved in the assembly as a function of the
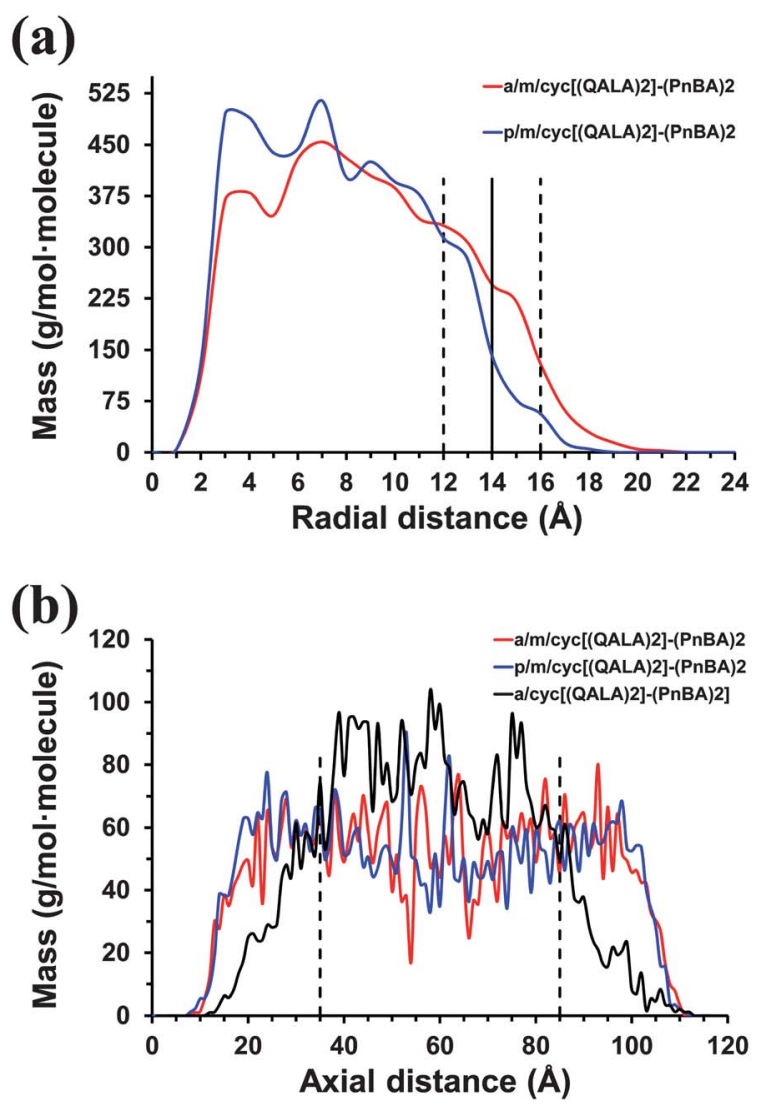

Fig. 13 Distribution of mass per molecule involved in the assemblies deposited on mica as a function of the (a) radial and (b) axial distance (i.e. perpendicular and parallel to the mica surface, respectively) from the center of mass. The mass distribution along the axial distance for the hybrid in solution, a/cyc $\left[(\mathrm{QALA})_{2}\right]-(\mathrm{PnBA})_{2}$, has been included in (b). In the latter case, the axis has been defined by the Lys residues that incorporate the polymer chains. The solid line in (a) indicates the experimental value of $h$ while dashed lines reflect the uncertainty $(h=14 \pm 2 \AA)$. The dashed lines in (b) delimit the value of $w$ estimated using AFM ( $w=50 \AA)$. 
radial distance (i.e. perpendicular to the surface) from the center of mass for the studied systems. As can be seen, both a/m/cyc $\left[(\mathrm{QALA})_{2}\right]-(\mathrm{P} n \mathrm{BA})_{2}$ and $\mathrm{p} / \mathrm{m} / \mathrm{cyc}$ $\left[(\mathrm{QALA})_{2}\right]-(\mathrm{P} n \mathrm{BA})_{2}$ show a broad tail that vanished at $r \approx 21 \AA$. The theoretical value of $h$ was estimated as the distance at which the radial mass profile has dropped to half of its maximum value before reaching the external layer of the nanotube section. The predicted $h$ value for a/m/cyc $\left[(\mathrm{QALA})_{2}\right]-(\mathrm{P} n \mathrm{BA})_{2}$ and $\mathrm{p} / \mathrm{m} /$ cyc $\left[(\mathrm{QALA})_{2}\right]-(\mathrm{P} n \mathrm{BA})_{2}$ is 14.5 and $13.5 \AA$, respectively, in excellent agreement with the experimental measurement $(14 \pm 2 \AA) .{ }^{21}$

Unfortunately, determination of a parameter analogous to $h$ for the hybrid in solution is not possible because of both the lack of a reference surface and arrrangement of the PnBA chains in solution. However, adsorption-induced deformation has been evaluated by calculating the diameter of the nanotube in the following three ways: (i) considering all the backbone atoms of the cyclopeptide $\left(D_{\mathrm{b}}\right)$; (ii) considering the radial distance between side chains of confronted Ala residues of the same cyclopeptide $\left(D_{\mathrm{Ala}}\right)$; and (iii) considering the radial distance between side chains of confronted Gln residues of the same cyclopeptide $\left(D_{\mathrm{Gln}}\right)$. The $D_{\mathrm{b}}, D_{\mathrm{Ala}}$ and $D_{\mathrm{Gln}}$ values estimated for the antiparallel hybrid in solution are $9.46 \pm 0.12,12.51 \pm 0.23$ and $17.58 \pm 2.26 \AA$, respectively, whereas the values for $\mathrm{a} / \mathrm{m} / \mathrm{cyc}\left[(\mathrm{QALA})_{2}\right]-(\mathrm{P} n \mathrm{BA})_{2}$ are $9.22 \pm 0.26,12.76 \pm 12$. and $17.17 \pm 1.38 \AA$, respectively. These results indicate that adsorption produces a small radial deformation, which has been estimated to be $\sim 0.2 \AA$.

Fig. 13b shows the distribution of mass per molecule involved in the assemblies deposited on mica as a function of the axial distance (i.e. parallel to the surface) from the center of mass for the studied systems. The mass is approximately constant from $\sim 20$ to $\sim 95 \AA$, tailing off at shorter and larger distance, respectively. The theoretical $w$ value obtained considering the distance at which the axial mass profile has dropped to half of the constant value is 84 and $87 \AA$ for $\mathrm{a} / \mathrm{m} / \mathrm{cyc}\left[(\mathrm{QALA})_{2}\right]-(\mathrm{P} n \mathrm{BA})_{2}$ and $\mathrm{p} / \mathrm{m} / \mathrm{cyc}\left[(\mathrm{QALA})_{2}\right]-(\mathrm{P} n \mathrm{BA})_{2}$, respectively. These values are $\sim 20 \%$ shorter than those expected for a fully extended conformation, which should be attributed to both the deformation induced by the adsorption process and the contraction produced by the attractive mica-PnBA interactions. Thus, for an ideal zig-zag arrangement the expected molecular width is [(length of the P $n$ BA repeat unit: $2.5 \AA) \times 16$ repeat units] $\times 2$ P $n$ BA chains + (length of the linker: $8.75 \AA$ ) $\times 2$ linkers + (radius of the peptide: $14 \AA$ ) $=111 \AA$. However, the experimental width approximately determined by AFM was $\sim 50 \AA{ }^{21}$ which indicates that the contraction with respect to the ideal all-trans conformation is underestimated by MD simulations. Thus, the model predicted by theoretical calculations consists of a peptide core built via the stacking of $\beta$-sheet cyclopeptides and surrounded by a shell of semi-extended polymer chains, whereas AFM observations indicate that the polymer shell surrounding the hollow nanotube is composed of folded chains and, therefore, is shorter than predicted by theoretical calculations. In order to explain this discrepancy, additional analyses were carried out.

Fig. 13b includes the distribution of mass per molecule as a function of the axial distance for the antiparallel hybrid in DMF solution, where the axis is defined by the Lys residues attached to the polymer chains. It should be noted that $\mathrm{P} n \mathrm{BA}$ chains are distributed along this axis (i.e. this is largest axis). Therefore, the resulting $w$ value is expected to be comparable to that obtained for the nanotube deposited on mica, which is not possible for $h$. As can be seen, the width 
is lower than those predicted for assemblies deposited on mica, this feature being consistent with the partial radial distribution functions calculated for the $\mathrm{CH}_{2}$-CHR pairs (Fig. 12). More specifically, the mass is roughly constant for distances ranging from 35 to $82 \AA$, decreasing rapidly outside of this interval. The value of $w$ predicted for a/cyc[(QALA $\left.)_{2}\right]-(\mathrm{P} n \mathrm{BA})_{2}$, which was determined by applying the procedure used above for systems deposited on mica, is $54 \AA$. Interestingly, the latter is in excellent agreement with the value determined experimentally for the desolvated systems adsorbed onto the mica surface. This feature suggests two alternative explanations to justify the discrepancy between the $w$ values predicted for the assembly deposited on mica and the AFM measurement. The first one refers to the fact that the hybrid is not completely desolvated, as was considered in the theoretical model. Thus, solvent molecules entrapped in the polymer shell may help to maintain the partially folded conformation of $\mathrm{P} n \mathrm{BA}$ by mitigating, in part, the polymer-surface attractive interactions. The second explanation, and indeed the most probable source of error, corresponds to differences in the deposition process. More specifically, for the experiments nanotubes were deposited onto the mica surface within a solvated environment, desolvation being carried out in a subsequent stage for AFM measurements. In contrast, simulations were performed by depositing the nanotube in a completely desolvated environment. This means that folded and semi-extended PnBA chains were directly deposited in the experiment and theoretical model, respectively. Due to the strong interaction between the surface and the polymer chains, no conformational rearrangement was allowed during the MD simulations in the latter case.

\section{Conclusions}

Atomistic MD simulations of cyc[(L-Gln-D-Ala-L-Lys-D-Ala $\left.)_{2}\right]$ and cyc[(L-Gln-D-Ala-LLys-D-Ala $\left.)_{2}\right]-(\mathrm{P} n \mathrm{BA})_{2}$ nanotubes have been used to get new structural insights at the microscopic level that are in part inaccessible to experimental techniques. Simulations of nanostructures constructed using parallel and antiparallel configurations show that the former is unstable in solution because of the structural deformations produced by the formation of side chain-backbone interactions. The fragmentation of the parallel assembly in solution is due to the disruption of the stabilizing intermolecular hydrogen bonds, which is induced by the Lys side group. The two configurations are stable when the tubelike assembly is desolvated and deposited on mica. Energy analyses reveal that, under such conditions, the parallel configuration is stabilized by the formation of strong attractive interactions between the PnBA chains and the mica substrate.

The dynamical effects associated with the nanotubular assembly in solution have been found to be significantly reduced by the attractive interactions exerted by the mica surface. The inter-subunit distance of the systems deposited in mica undergoes a small contraction $(\sim 0.15 \AA)$ with respect to the calculated in solution. This feature matches experimental observations derived from Fourier-transform infrared spectroscopy and electron diffraction. Furthermore, simulations indicate that the adsorption of the hybrid assembly onto the mica surface results in a small reduction of both the peptide ring circularity and the internal van der Waals diameter. On the other hand, analysis of distances between $\mathrm{CH}_{2}-\mathrm{CHR}$ indicates some order in the PnBA chains at both the intramolecular and intermolecular 
level, this feature being more remarkable for systems deposited on mica than those in DMF solution.

Structural studies on the hybrid deposited on mica have allowed us to reproduce the height experimentally determined by AFM. In contrast, the totally desolvated model used in this work overestimates the observed width. This has been attributed to the strong attractive interactions between the mica surface and polymer chains, which preclude conformational changes in the latter. Consideration of the solvent molecules during the deposition process may help to retain the partially folded conformation predicted in DMF solution. This would be consistent with the view of a hollow nanotube surrounded by a shell of partially folded PnBA chains.

In summary, atomistic computer simulations on complex systems, such as assembled peptide-polymer conjugates, provide microscopic details that are not easily accessible at the experimental level. Thus, computer simulations play an increasingly important role in the biomolecular and biomaterials sciences. Although continuous progress is being made in the development of experimental analysis methods, computational techniques are currently the only possibility for atomic-resolution analyses of many complex systems. Although here we have largely focused on nanotubes, we believe that atomistic simulation techniques combined with experimental data offer useful tools for the rational design of an almost unlimited range of architectures and applications based on peptidepolymer conjugates.

\section{Acknowledgements}

Financial support from the MICINN and FEDER (MAT2012-34498) and Generalitat de Catalunya (research group 2009 SGR 925 and XRQTC) is gratefully acknowledged. Support for the research of C. A. was received through the prize "ICREA Academia" for excellence in research funded by the Generalitat de Catalunya. Authors are indebted to the Centre de Supercomputació de Catalunya (CESCA) for the computational resources provided. The authors thank Dr Hendrik Heinz, who kindly supplied the mica super cell model constructed in ref. 61.

\section{References}

1 J.-F. Lutz and H. G. Borner, Prog. Polym. Sci., 2008, 33, 1-39.

2 F. M. Veronese and J. M. Harris, Adv. Drug Delivery Rev., 2002, 54, 453-609.

3 D. Eckhardt, M. Groenewolt, E. Krause and H. G. Borner, Chem. Commun., 2005, 22, 2814-2816.

4 J. Hentschel, E. Krause and H. G. Borner, J. Am. Chem. Soc., 2006, 128, 7722-7723.

5 I. W. Hamley, M. J. Krysmann, V. Castelletto and L. Noirez, Adv. Mater., 2008, 23, 43944397.

6 M. Pechar, P. Kopeckova, L. Joss and J. Kopecek, Macromol. Biosci., 2002, 2, 199-206.

7 I. W. Hamley and M. J. Krysmann, Langmuir, 2008, 24, 8210-8214.

8 F. M. Veronese, Biomaterials, 2001, 22, 405-17.

9 G. M. Whitesides, Small, 2005, 1, 172-179.

10 S. Zhang, Nat. Biotechnol., 2003, 21, 1171-1178.

11 R. S. Tu and M. Tirrell, Adv. Drug Delivery Rev., 2004, 56, 1537-63.

12 K. L. Heredia and H. D. Maynard, Org. Biomol. Chem., 2007, 5, 45-53.

13 J.-F. Lutz and H. G. Borner, Prog. Polym. Sci., 2008, 33, 1-39.

14 M. A. Gauthier and H.-A. Klok, Chem. Commun., 2008, 23, 2591-2611.

15 H. G. Börner, Prog. Polym. Sci., 2009, 34, 811-851.

16 J. Hentschel, E. Krause and H. G. Borner, J. Am. Chem. Soc., 2006, 128, 7722-7723. 
17 T. S. Burkoth, T. L. S. Benzinger, V. Urban, D. G. Lynn, S. C. Meredith and P. Thiyagarajan, J. Am. Chem. Soc., 1999, 121, 7429-7430.

18 H. A. Lashuel, S. R. LaBrenz, L. Woo, L. C. Serpell and J. W. Kelly, J. Am. Chem. Soc., 2000, 122, 5262-5277.

19 J.-F. Lutz and H. G. Borner, Prog. Polym. Sci., 2008, 33, 1-39.

20 J. D. Hartgerink, J. R. Granja, R. A. Milligan and M. R. Ghadiri, J. Am. Chem. Soc., 1996, 118, 43-50.

21 M. G. J. ten Cate, N. Severin and H. G. Borner, Macromolecules, 2006, 39, 7831-7838.

22 X. Gao and H. Matsui, Adv. Mater., 2005, 17, 2037-2050.

23 I. Hamley, Soft Matter, 2011, 7, 4122-4138.

24 T. P. J. Knowles and M. J. Buehler, Nat. Nanotechnol., 2011, 6, 469-479.

25 Y. Xuehai, Z. Penglu and L. Junbai, Chem. Soc. Rev., 2010, 39, 1877-1890.

26 N. Haspel, D. Zanuy, C. Alemán, H. Wolfson and R. Nussinov, Structure, 2006, 14, 11371148.

27 N. Haspel, D. Zanuy, J. Zheng, C. Alemán, H. Wolfson and R. Nussinov, Biophys. J., 2007, 93, 245-253.

28 J. Jenkins, O. Mayans and R. Pickersgill, J. Struct. Biol., 1998, 122, 236-246.

29 S. Kwon, H. S. Shin, J. Gong, J. H. Eom, A. Jeon, S. H. Yoo, I. S. Chung, S. J. Cho and H. S. Lee, J. Am. Chem. Soc., 2011, 133, 17618-17621.

30 M. Swain, R. Thirupathi, B. Krishnarjuna, E. M. Eaton, M. M. Kibbey, S. A. Rosenzweig and H. S. Atreya, Chem. Commun., 2010, 46, 216-218.

31 M. R. Ghadiri, J. R. Granja and L. K. Buehler, Nature, 1994, 369, 301-304.

32 D. T. Bong, T. D. Clark, J. R. Granja and M. R. Ghadiri, Angew. Chem., Int. Ed., 2001, 40, 988-1011.

33 R. Brea, C. Reiriz and J. R. Granja, Chem. Soc. Rev., 2010, 39, 1448-1456.

34 M. R. Ghadiri, J. R. Granja, R. A. Milligan, D. E. McRee and N. Khazanovich, Nature, 1993, 366, 324-327.

35 T. D. Clark, J. M. Buriak, K. Kobayashi, M. P. Isler, D. E. McRee and M. R. Ghadiri, J. Am. Chem. Soc., 1998, 120, 8949-8962.

36 J. Couet, J. D. J. S. Samuel, A. Kopyshev, S. Santer and M. Biesalski, Angew. Chem., Int. Ed., 2005, 44, 3297-3301.

37 R. Chapman, K. A. Jollife and S. Perrier, Polym. Chem., 2011, 2, 1956-1963.

38 T. Xu, N. Zhao, F. Ren, R. Hourani, M. T. Lee, J. Y. Shu, S. Mao and B. A. Helms, ACS Nano, 2011, 5, 1376-1384.

39 S. Loschonsky, J. Couet and M. Biesalski, Macromol. Rapid Commun., 2008, 29, 309-315.

40 J. Couet and M. Biesalski, Small, 2008, 4, 1008-1016.

41 M. R. Ghadiri, J. R. Granja, R. A. Milligan, D. E. McRee and N. Khazanovich, Nature, 1993, 366, 324-327.

42 R. Vijayaraj, S. Van Damme, P. Bultinck and V. Subramanian, Phys. Chem. Chem. Phys., 2013, 43, 15135-15144.

43 R. Vijayaraj, S. S. Raman, R. M. Kumar and V. Subramanian, J. Phys. Chem. B, 2010, 114, 16574-16583.

44 I. Buch, B. R. Brooks, H. J. Wolfson and R. Nussinov, Nano Lett., 2009, 3, 1096-1102.

45 G. Ballano, D. Zanuy, A. I. Jiménez, C. Cativiela, R. Nussinov and C. Alemán, J. Phys. Chem. B, 2008, 112, 13101-13115.

46 C. A. Palma, M. Cecchini and P. Samori, Chem. Soc. Rev., 2012, 41, 3713-3730.

47 N. V. Buchete, R. Tycko and G. Hummer, J. Mol. Biol., 2005, 353, 804-821.

48 G. Colombo, P. Soto and E. Gazit, Trends Biotechnol., 2007, 25, 211-218.

49 D. Zanuy, I. W. Hamley and C. Alemán, J. Phys. Chem. B, 2011, 115, 8937-8946.

50 N. Haspel, A. Laurent, D. Zanuy, R. Nussinov, C. Alemán, J. Puiggalí and G. Revilla-López, J. Phys. Chem. B, 2012, 116, 13941-13952.

51 A. Jain and H. S. Ashbaugh, Biomacromolecules, 2011, 12, 2729-2734.

52 O. Bertran, B. Zhang, A. D. Schlüter, A. Halperin, M. Kröger and C. Alemán, RSC Adv., 2013, 3, 126-140.

53 W. D. Cornell, P. Cieplak, C. I. Bayly, I. R. Gould, K. M. Merz, D. M. Ferguson, D. C. Spellmeyer, T. Fox, J. W. Caldwell and P. A. Kollman, J. Am. Chem. Soc., 1995, 117, 5179-5197.

54 Y. Duan, C. Wu, S. Chowdhury, M. C. Lee, G. M. Xiong, W. Zhang, R. Yang, P. Cieplak, R. Luo, T. Lee, J. Caldwell, J. Wang and P. A. Kollman, J. Comput. Chem., 2003, 24, 1999-2012.

55 T. Z. Lwin and R. Luo, Protein Sci., 2006, 15, 2642-2655.

56 E. A. Cino, W. Y. Choy and M. Karttunen, J. Chem. Theory Comput., 2012, 8, 2725-2740.

57 J. Wang, R. M. Wolf, J. W. Caldwell, P. A. Kollman and D. A. Case, J. Comput. Chem., 2004, 25, 1157-1174.

58 W. L. Jorgensen, J. M. Briggs and M. L. Contreras, J. Phys. Chem., 1990, 94, 1683-1686. 
59 W. L. Jorgensen, D. S. Maxwell and J. Tirado-Rives, J. Am. Chem. Soc., 1996, 118, 1122511236.

60 G.-Z. Jia, K.-M. Huang, L. J. Yang and X.-Q. Yang, Int. J. Mol. Sci., 2009, 10, 1590-1600.

61 H. Heinz, H. Koerner, K. L. Anderson, R. A. Vaia and B. L. Farmer, Chem. Mater., 2005, 17, 5658-5669.

62 R. Rothbauer, Neues Jahrb. Mineral., Monatsh., 1971, 143-154.

63 A. Toukmaji, C. Sagui, J. Board and T. Darden, J. Chem. Phys., 2000, 113, 10913-10927.

64 J. C. Phillips, R. Braun, W. Wang, J. Gumbart, E. Tajkhorshid, E. Villa, C. Chipot, R. D. Skeel, L. Kale and K. Schulten, J. Comput. Chem., 2005, 26, 1781-1802.

65 H. J. C. Berendsen, J. P. M. Postma, W. F. van Gunsteren, A. DiNola and J. R. Haak, J. Chem. Phys., 1984, 81, 3684-3690.

66 J. P. Ryckaert, G. Ciccotti and H. J. C. Berendsen, J. Comput. Phys., 1977, 23, 327-341.

67 M. Engels, D. Bashford and M. R. Ghadiri, J. Am. Chem. Soc., 1995, 117, 9151-9158.

68 P. DeSantis, S. Morosetti and R. Rizzo, Macromolecules, 1974, 7, 52-58.

69 S. S. Sheiko, S. A. Prokhorova, K. L. Beers, K. Matyjaszewski, I. I. Potemkin, A. R. Khokhlov and M. Moller, Macromolecules, 2001, 34, 8354-83600.

70 S. S. Sheiko and S. S. Moller, Chem. Rev., 2001, 101, 4099-4123.

71 J. Pyun, T. Kowalewski and K. Matyjaszewski, Macromol. RapidCommun., 2003, 24, 10431059.

72 B. Zhang, R. Wepf, M. Kröger, A. Halperin and A. D. Schlüter, Macromolecules, 2011, 44, 6785-6792. 